\title{
ESPIRITUALIDAD PARA LA MISIÓN
}

Fecha de recepción: 05 de diciembre de 2019

Fecha de aceptación: 29 de enero de 2020

RESUMEN: Una de las características del ministerio pastoral del papa Francisco es la insistencia en asumir con un nuevo impulso la responsabilidad cristiana de anunciar del Evangelio. En este sentido, su magisterio se sitúa en perfecta continuidad con las perspectivas abiertas por el Concilio Vaticano II para la Iglesia en el mundo contemporáneo. Buena parte del pensamiento teológico de los últimos decenios ha mostrado la intrínseca correlación entre la misión eclesial y la espiritualidad. Basándose en los textos del Concilio y en las contribuciones de algunos destacados teólogos de la generación conciliar, esta reflexión pretende evidenciar los fundamentos teológicos de un renovado impulso misionero en la Iglesia desde la correlación entre la espiritualidad y la misión, especialmente, a la luz de los consejos evangélicos de pobreza, castidad y obediencia, en cuanto dinamismos de la vida teologal.

PALABRAS CLAVE: espiritualidad; misión; Concilio Vaticano II; consejos evangélicos; virtudes teologales.

\section{Spirituality for Mission}

ABSTRACT: One of the characteristics of the pastoral ministry of Pope Francis is the insistence on assuming with a new impulse the Christian responsibility of proclaiming the Gospel. In this sense, his magisterium is situated in perfect continuity with the perspectives opened up by the Second Vatican Council for the Church in

* Universidad Pontificia Comillas: ssueiro@comillas.edu; ORCID: https://orcid. org/0000-0001-5940-3531 
the contemporary world. Much of the theological thinking of recent decades has shown the intrinsic correlation between ecclesial mission and spirituality. Based on the Council's texts and on the contributions of some outstanding theologians of the conciliar generation, this reflection seeks to highlight the theological foundations of a renewed missionary impulse in the Church from the correlation between spirituality and mission, especially in the light of the evangelical counsels of poverty, chastity and obedience, as dynamisms of the theological life.

KEY WORDS: spirituality; mission; second Vatican Council; evangelical counsels; theological virtues.

Pragmáticos como somos, solemos caer en la tentación de llenar de contenido apresuradamente las cuestiones que la vida nos plantea. Sería relativamente fácil desgranar una serie de rasgos que haya de tener nuestra espiritualidad para ser misionera o servir a la misión. Y no estaría de más que al final de estas páginas hubiéramos dado con alguna pista para la vida en este sentido. Sin embargo, quisiéramos que nuestra reflexión sirviera para llevar la cuestión a su profundidad. ¿Qué significa que debamos vivir una espiritualidad para la misión y cómo se entiende esto en nuestros tiempos? Comencemos, por ello, con unas palabras que pueden describir el tiempo de zozobra que nos ha tocado vivir:

«La inquietud actual es producto de la mezcla de una serie de factores difíciles, o casi imposibles, de analizar: miedo ante lo nuevo y ante el afán casi salvaje de innovar por el mero hecho de que lo nuevo es nuevo y resulta "más interesante"; inquietud realmente creadora, que pone con todo derecho sus miras a lo nuevo, y lo busca como una realización más auténtica de la vida cristiana y de la Iglesia; temor ante la inestabilidad de la situación en la que actualmente viven la Iglesia y los fieles; debilitamiento de la auténtica fortaleza de la fe, que falla ante las acometidas del mundo moderno. Para que la Iglesia sea lo que debe ser hay que aceptar esta situación de inquietud, hay que sobrellevarla con paciencia, y hay que intentar comprenderla y superarla progresivamente. Ni siquiera la Iglesia puede elegir la situación en que ha de vivir. Le es dada. Y es bueno que así sea» ${ }^{1}$.

\footnotetext{
1 Karl Rahner. "Espiritualidad antigua y actual”. En Escritos de teología. Vol. 7. Madrid: Taurus, 1969, 13-35 (aquí, 13-14). 
En nuestros días, más de uno suscribiría de buen grado, si no todas estas afirmaciones, sí al menos el diagnóstico inicial como descripción del panorama en que nos hallamos. Ciertamente, la conciencia creyente parece verse envuelta en miedos, inquietudes y temores a la hora de comprenderse y de buscar la respuesta adecuada a la que la invita su propia vocación. Sin embargo, el retrato con el que se abren estas páginas no es nuevo: hace más de medio siglo que sirvió a K. Rahner como punto de partida para discernir los desafíos y las tareas de un renovado modo de vivir la espiritualidad en la Iglesia².

¿Quién no habla —o ha oído hablar- en nuestros días de miedo, inquietud, temor, debilitamiento...? Otros prefieren seguir echando mano del término «crisis» - palabra talismán—, si bien descuidan que la misma inflación del discurso sobre la crisis es proporcional a nuestros miedos, porque por un lado no sabemos resolverla y, por otro, no sabemos definir$l^{3}{ }^{3} .$. Sean cuales fueren los términos del diagnóstico actual, unos y otros podemos convenir en que nuestra situación actual está determinada por el hecho del «cambio». Vivimos tiempos de transformación —ojalá también de verdadera "conversión»-, si bien el cambio ha sido una constante a lo largo de la historia de la humanidad. En este sentido, quizá hayamos interiorizado demasiado ingenuamente la idea de que las generaciones que nos precedieron no tuvieron que lidiar tanto como nosotros con los cambios y novedades, porque — creemos- su época estaba marcada por

2 Este trabajo sirvió de esquema para una conferencia pronunciada por el teólogo de Friburgo en diversas ciudades alemanas y fue publicado por vez primera en Karl Rahner. "Frömmigkeit heute und morgen”. Geist und Leben 39, n. ${ }^{\circ} 5$ (1966): 326-342 [posteriormente, publicado como "Frömmigkeit früher und heute". En Schriften zur Theologie VII. Zur Theologie des geistlichen Lebens. Einsiedeln - Zürich - Köln: Benziger, 1966, 11-31; y en Sämtliche Werke. Vol. 23, 31-46].

3 Con tanta lucidez como ironía, así se expresaba hace ya bastantes años, el filósofo francés J.-L. Marion: «L'inflation du discours sur la " crise " est proportionnelle à nos peurs. [...] De ce qu'il est aujourd'hui convenu de nommer " la crise ”, deux choses (et sans doute guère plus) sont avérées: d'abord que nous ne savons pas la résoudre ; et que, très vraisemblablement, nous ne savons pas la définir. [...] Si nous possédions un concept précis de la " crise " et si nous pouvions l'appliquer rigoureusement à la situation présente, il intégrerait une majorité de ses aspects, qui sont aujourd'hui éclatés et seulement juxtaposés. Il faut donc supposer une crise du concept de "crise", avant même toute crise de notre société ou de notre époque. À moins que la prétendue " crise " de notre monde ne se décèle précisément à la crise de la notion même de "crise" (Jean-Luc Marion. "La crise et la Croix ”. Communio. Revue Catholique Internationale 8, n. 4 [1983]: 8). 
el signo de la estabilidad y la usanza. Probablemente un sencillo repaso por la historia de nuestra cultura y de nuestra tradición eclesial bastaría para disipar tal quimera. ¿Acaso no es verdad que toda época es época de cambios y que en todo tiempo los cristianos han tenido que buscar caminos para ser santos recios, para hallar esa parresía que consiste en hacer del Señor su único sostén y arrostrar «por Él, con Él y en Él» los vaivenes más insospechados, dejándose configurar por la gracia de Dios?

Lo que tal vez no todos se atrevan a pronunciar sobre nuestro presente son las palabras que coronan la descripción de K. Rahner, admitiendo que la Iglesia no puede «elegir la situación en que ha de vivir. Le es dada. Y es bueno que así sea». No pocas veces, los síntomas de malestar o los lamentos enmascaran perezas, inercias y autojustificaciones que no nos hacen ningún bien, porque nos tornan estériles. Habría que pensar que, más que amenazas o debilidades, las características de nuestra época son expresión de la incomprensibilidad misma de la vida. A veces olvidamos que la urdimbre de nuestra biografía no se teje con programas, técnicas, recursos, planificaciones, control... sino que, en su ultimidad, la trama se entrecruza de encuentros, inseguridades, gracias, vidas y misterios tejidos por la fe y el amor. Por eso, siempre nos cabe la esperanza fundada de ver la otra cara de lo que algunos llaman crisis: la de las posibilidades y oportunidades, la de la libertad y responsabilidad, que se nos brinda para abrazar con determinación el misterio de nuestra existencia.

Quizá nos ayude, en este sentido, detenernos en el contenido existencial de la fe presente en los dos conceptos centrales de nuestro tema: la espiritualidad y la misión. ¿Qué son? ¿Desde dónde hemos de vivirlas siempre? ¿Cómo habría que encarnarlas hoy?

\section{ESPIRITUALIDAD}

\subsection{Desentrañando un Concepto}

Brevemente situados en nuestro contexto, comencemos por desentrañar el primero de los conceptos que hemos de abordar: ¿a qué nos referimos cuando hablamos de "espiritualidad»? Se ha convertido ya en un lugar común decir que bajo el paraguas de este término podemos referirnos a una multiplicidad bastante amplia de cosas y que, por ende, es 
preciso aclarar qué queremos decir con ella. Así como ocurre con el de la crisis, el discurso sobre la espiritualidad también sufre una considerable inflación, con el riesgo de devaluación que esto conlleva. Lo cual podría explicarse por lo reciente y amplio del término «espiritualidad», que comenzó a desempeñar un papel específico dentro del lenguaje teológico de una generación a esta parte. Buena parte de lo que hoy comprendemos bajo tal concepto se expresaba antaño con el término «piedad» (religiosidad, devoción...). Con él no se nombra únicamente el acto religioso en sí, sino también el hecho de organizar y vivir la propia existencia a la luz de la fe y, por consiguiente, al dinamismo que nos lleva a integrar armónicamente en fe la oración personal, la conducta moral, las expresiones rituales, etc. En resumidas cuentas, la «espiritualidad» de hoy o la «piedad» de antaño apuntaban al modo en que alguien vive la propia fe en todas las dimensiones de su existencia ${ }^{4}$. Como bien explica G. Greshake:

«No es fácil definir qué es realmente espiritualidad. Pues, antes que cualquier explicación conceptual, designa una forma de vida, y esto significa para un cristiano la actitud fundamental vivida de la fe y la entrega vivida del hombre a Dios y a su causa. Por eso mismo, la espiritualidad es tan compleja como la vida misma y como el abanico de posibilidades en las formas de relación con Dios. Ya la raíz lingüística misma de espiritualidad subraya que la vida desde la fe es esencialmente una vida "en el Espíritu" y "desde el Espíritu”. Más aún: es obra del Espíritu Santo. Él, el Espíritu, realiza la espiritualidad. Por eso, según la comprensión cristiana, espiritualidad es, ante todo, algo que me es regalado por el Espíritu de Dios y que "acontece" en mí. No es ni un proyecto orquestado por mí ni se identifica con un determinado plan de vida, ni con formas fijas de piedad o modos de comportamiento que yo mismo voy ensayando (aunque ella requiera la ejercitación de formas cada vez más estables). El iniciador y sujeto primordial de toda espiritualidad es siempre el Espíritu Santo» ${ }^{5}$.

Quienes han tratado de ofrecer una definición general de «espiritualidad», pretendiendo que dicho concepto pueda hacer justicia a su esencia genuina, pero intentando al mismo tiempo que sirva para abarcar otros ámbitos existenciales, suelen referirse a «lo espiritual» como a todo un amplio campo en que se da una relación dinámica del ser humano como

4 Cf. Gisbert Greshake. ... wie man in der Welt leben soll. Grundfragen christlicher Spiritualität. Würzburg: Echter, 2009, 10-12.

5 Cf. ibid., 12. 
espíritu con el Espíritu divino. Así considerado, «lo espiritual» haría referencia a los aspectos tanto ascéticos como místicos de dicha relación, además de conjugar tradiciones bíblicas e intuiciones filosóficas, a sabiendas de que «espiritualidad» rebasa los límites de las religiones y las filosofías de la vida ${ }^{6}$.

Dicho de otro modo, el concepto de espiritualidad denota el proceso relacional que existe entre Dios y el hombre, ya sea acentuando los aspectos más característicos del polo divino, ya sea los del polo humano. Una relación que suele entenderse como un proceso de personalización intensivo, purgativo y unificador, que - aunque situado en el ámbito de la intimidad - conduce a la transformación de la conducta y de las propias potencias personales - memoria, entendimiento y voluntad- ${ }^{7}$.

A partir de esta definición general, resulta relativamente sencillo vislumbrar que la espiritualidad tiene mucho que ver con la incomprensibilidad de la vida, antes citada. Si bien es cierto que todo cambio puede generar miedo e inseguridad, no lo es menos que puede resultar una oportunidad y una posibilidad de crecimiento. Sin duda, esta segunda opción se nos antoja más provechosa para un acercamiento espiritual a la realidad y, más aún, para una comprensión misionera de la espiritualidad. De igual modo que a K. Rahner le parecía «bueno» para la Iglesia el dejarse interpelar por las posibilidades del mundo de entonces, también a nosotros nos resultará fecundo emprender un discernimiento evangélico sobre nuestro tiempo para percibir en él las ocasiones de gracia a las que el Espíritu nos puede estar llamando.

No obstante, antes de adentrarnos en las dimensiones de una espiritualidad misionera en nuestro mundo de hoy, detengámonos en explicar la triple dinámica en que se desarrolla toda espiritualidad.

6 Cf. Kees Waaijman. Espiritualidad. Formas, fundamentos y métodos. Salamanca: Sígueme, 2011, 386-391.

7 Cf. ibid., 390; Aimé Solignac. "Spiritualité (I. Le mot et l'histoire)”. En Dictionnaire de Spiritualité ascétique et mystique. Doctrine et histoire, dirigido por Marcel Viller y Ferdinand Cavallera. Vol. 14, 1142-1160. Paris: Beauchesne, 1990; Lucy Tinsley. The French Expressions for Spirituality and Devotion. A Semantic Study. New York: Catholic University of America Press, 1953; Margaret Chatterjee. The Concept of Spirituality. Ahmedabad: Allied Publishers, 1989; Sant Kirpal Singh. Was ist Spiritualität? Bern: Origo, 1983. Una buena presentación del amplísimo panorama de definiciones acerca del concepto «espiritualidad» en Eulogio Pacho. "Definición de la 'espiritualidad'. Respuestas y tratamientos”. Burgense 34, n. ${ }^{\circ} 1$ (1993): 281-302. 


\subsection{TRES DIMENSIONES DE LA ESPIRITUALIDAD}

En la misma época en que K. Rahner describía los síntomas del contexto en que se hacía necesaria una manera renovada de vivir la espiritualidad, otro gran teólogo del siglo XX, H. U. von Balthasar, publicaba una pequeña reflexión que puede aportar cierta luz a la cuestión que nos ocupa.

En el tercer volumen de sus Ensayos teológicos, el teólogo de Lucerna invita a pensar «el Evangelio como norma y criterio de toda espiritualidad en la Iglesia» ${ }^{8}$. Para ello, comienza por distinguir las tres dimensiones de toda espiritualidad humana: a) por un lado, «espiritualidad» hace referencia al hombre, «que, para diferenciarse del mundo y de los animales, se define a través del espíritu ^"; b) por otro lado, esta relación entre el hombre y su circunstancia no se conforma con ser una mera tendencia o predisposición difusa, sino que el espíritu humano busca "realizarse», quiere comprehender la totalidad y, para ello, convertirse en «decisión» y principio de acción; c) finalmente, existe una tercera dimensión propia de la «espiritualidad» humana que se descubre al considerar que dicha dinámica espiritual solo llega a su mismidad y «alcanza su perfección cuando el que actúa no toma como norma el anhelo de lo absoluto», sino "cuando deja que sea el absoluto el que disponga como espíritu normativo" y marque la pauta ${ }^{10}$.

A riesgo de simplificar en exceso, diríamos que —en síntesis- toda verdadera espiritualidad integra en sí una relación de búsqueda de Dios en fe, su repercusión concreta en la propia existencia y el consentimiento a que Él lleve la iniciativa en dicha relación.

a) En la primera dimensión, ha de encuadrarse nuestra capacidad de ir «de la dispersión a la concentración, de lo caduco a lo estable, de la alienación de uno mismo a lo arraigado en el propio centro». En esta dirección tiene su lugar "la irrupción de todo pensamiento filosófico en la teoría en cuanto búsqueda filosófica y existencial de la verdad de la existencia» ${ }^{11}$. Concebida como itine-

8 Cf. Hans Urs von Balthasar. "El Evangelio como norma y criterio de toda espiritualidad en la Iglesia”. En Spiritus Creator. Ensayos teológicos III. Madrid: Encuentro - Cristiandad, 2004, 233-247 [original en "Das Evangelium als Norm und Kritik aller Spiritualität in der Kirche”. Concilium 1, n. ${ }^{\circ} 9$ (1965): 715-722].

9 Ibid., 234.

10 Ibid., 235.

11 Ibid., 234. 
rario del hombre "hacia adentro» de su existencia para buscar la verdad - dice H. U. von Balthasar- , la espiritualidad es «eros», «desiderium», «anámnesis» y «elpís». Ante la incomprensibilidad de la vida, el espíritu humano descubre la sed que lo habita y experimenta el asombro frente al misterio que todo lo trasciende.

b) Sin que desaparezca del horizonte la percepción de dicha incomprensibilidad, el ser humano constata que su búsqueda no es fruto de la pura abstracción, sino que lo implica en su concreción existencial. Esta es la segunda dimensión de toda espiritualidad, que nos mueve a la acción, a la disposición y a la toma de decisiones. Nadie puede mantener una vida espiritual auténtica apoyado en sus solos deseos y anhelos, sin que de su búsqueda afloren criterios y principios rectores de sus decisiones y acciones personales. Sería un error creer que la acción no forma parte de la espiritualidad. Con ello, estaríamos cayendo en un grave reduccionismo tanto a la hora de comprender la vida espiritual como a la hora de entender la acción. Sin que puedan ser confundidas, espiritualidad y acción están llamadas a integrarse mutuamente en unidad de vida.

c) Finalmente, queda una tercera dimensión por considerar. La «incomprensibilidad de la vida» no ha de pensarse como una idea vaga referida a los aspectos más enigmáticos de la condición humana. Que lo humano resulte radicalmente incomprensible no tiene tanto que ver con nuestra flaqueza a la hora de comprender la existencia, sino con el exceso de realidad que la vida misma es y con la trascendencia nos desborda. En este sentido, para ser auténtica, toda espiritualidad ha de abrirse a la presencia y la acción del Otro, de Dios: aun cuando es el hombre quien emprende el camino de la búsqueda y quien configura su itinerario con decisiones y acciones, no es él, sin embargo, quien marca la pauta y dispone los ritmos de la relación con el misterio. Es Dios mismo como misterio quien nos primerea, con expresión del papa ${ }^{12}$. Por eso, toda espiritualidad se caracteriza por afirmar la primacía del misterio de Dios, que - en cuanto trascendente- nunca se agotará en su darse y - en cuanto inmanente- precede con su sobreabundancia infinita la vida del hombre.

12 Francisco. Evangelii gaudium, n. 24. 
Estas tres dimensiones - diferenciables, aunque no disociables-que encontramos en toda «espiritualidad» pueden servirnos como marco para encuadrar las claves desde las que vivir la llamada a ser «Iglesia de Cristo en misión en el mundo" y tratar de comprender las implicaciones de una espiritualidad para la misión.

\section{MISIÓN}

\subsection{El DINAMISMO MISIONERO DEL AMOR DE Dios}

El segundo término que hemos de investigar para dar cuenta de nuestro tema es el de «misión». Para ello, permítasenos acudir a una imagen paradigmática que — afortunadamente- estará en el recuerdo de todos. No hace muchos años, Benedicto XVI advertía, en su primera encíclica, la necesidad de vivir nuestra existencia cristiana desde la primacía y la prioridad del amor de Dios: dado que Dios es amor que nos precede, el amor no es ya un mandato, sino una respuesta al don otorgado. Y con penetrante convencimiento, el entonces papa llamaba la atención sobre una tentación siempre al acecho: este amor que nos precede no puede conservarse de modo egoísta en el seno de la Iglesia, sino que, por su propio dinamismo, tiene vocación de rebasar las fronteras eclesiales ${ }^{13}$. Y es que, como recuerda el Catecismo de la Iglesia Católica, el fin último de la misión no es otro que el de hacer participar a los hombres en la comunión entre el Padre y el Hijo en su Espíritu de amor $^{14}$. O, como expresa el concilio Vaticano II:

«La Iglesia, al ayudar al mundo y recibir mucho de él, pretende una sola cosa: que venga el Reino de Dios y se instaure la salvación de todo el género humano. Todo el bien que el Pueblo de Dios puede aportar a la familia humana en el tiempo de su peregrinación terrena deriva del hecho de que la Iglesia es "sacramento universal de salvación", que manifiesta y realiza al mismo tiempo el misterio del amor de Dios al hombre» ${ }^{15}$.

\footnotetext{
13 Cf. Benedicto XVI. Deus caritas est, n. 25.

14 Cf. Catecismo de la Iglesia Católica, nn. 849-852.

15 GS 45a.
} 
A lo largo de los últimos cien años, la cuestión de la «espiritualidad misionera» ha ido apareciendo cada vez con mayor insistencia en los documentos del magisterio pontificio relativos a la misión. A pesar de la modestia con la que se va abriendo paso, resultaríamos gratamente sorprendidos al releer los textos dedicados al tema de la espiritualidad para la misión que encontramos en el magisterio de este último siglo ${ }^{16}$. Desde la exhortación de Benedicto XV, a comprender la misión como una vocación a dilatar las fronteras, no de los imperios humanos, sino las de Cristo, pasando por la advertencia de Pío XII, al declarar explícitamente que la Iglesia es misionera por propia vocación, y que «nada es más nocivo para su vida que el aislamiento», "el encerrarse en sí misma» ${ }^{17}$.

\subsection{LA APERTURA MISIONERA DEL CONCILIO VATICANO II}

Si ha habido un momento paradigmático en que la Iglesia ha comprendido su misión como vocación a vivir y transmitir el amor de Dios que la precede y constituye, ese ha sido el del kairós eclesial del concilio Vaticano II $^{18}$. En lugar de ceder a los miedos y recelos ante los desvíos o amenazas del mundo moderno, la asamblea conciliar supo dejarse guiar por el Espíritu para abrirse al hombre contemporáneo y reconocer en su situación nuevas posibilidades a la hora de vivir la fe. Así, los padres sinodales se atrevieron a preguntarse - en medio de grandes cambios- por las aspiraciones y los interrogantes más radicales del hombre, para secundar las mociones del Espíritu en su tiempo ${ }^{19}$. Y se propusieron, a la luz del misterio de Cristo, «hablar a todos para iluminar el misterio del hombre y para cooperar en el descubrimiento de la solución de los principales problemas de nuestro tiempo $»^{20}$. Para ello, comenzaron por declarar que:

16 Sobre la «espiritualidad misionera», cf. Benedicto XV. Maximum illud, 42-43 y 49-52; Pío XI. Rerum Ecclesiae, 57-58; Pío XII. Fidei donum, 12; Pablo VI. Evangelii nuntiandi, 75-80; Juan Pablo II. Slavorum apostoli, 30; Íd. Redemptoris missio, 87-91; Íd. Novo millenio ineunte, 43.

17 Cf. Pío XII. Fidei donum, 12.

18 Ya solo atendiendo a las ocasiones en que el corpus doctrinal del Concilio hace uso explícito de la familia léxica del término «misión» podemos contar un total de 288 (missio: 141; missionalis: 78; missionarius: 36; missus: 33).

19 Cf. GS 4-10 («Exposición preliminar: la condición del hombre en el mundo de hoy").

20 GS $10 b$. 
«El gozo y la esperanza, la tristeza y la angustia de los hombres de nuestro tiempo, sobre todo de los pobres y de todos los afligidos, son también gozo y esperanza, tristeza y angustia de los discípulos de Cristo y no hay nada verdaderamente humano que no tenga resonancia en su corazón» ${ }^{21}$.

Si antes nos hemos servido de sendas reflexiones de K. Rahner y H. U. von Balthasar publicadas en torno a 1965-1966, quisiéramos también en este punto traer a colación otro estudio de aquellos años. En sus primeros trabajos, un joven perito conciliar y acompañante del cardenal Frings - J. Ratzinger - caracterizaba todo el esfuerzo del Concilio Vaticano II como un profundo «movimiento de renovación», más que como una apertura ingenua al mundo. A su juicio, «el Concilio marcó el tránsito de un comportamiento conservador a uno misionero, y la oposición conciliar a lo conservador no es lo progresista, sino lo misionero» ${ }^{22}$. En efecto, en el plano teológico y eclesiológico, se trataba de salir de la sequedad de los esquemas neoescolásticos y juridicistas, de una cerrazón infecunda en el modo de plantear la vivencia de la fe frente al mundo y contra el fantasma del modernismo. Para superar aquel estrecho marco, el Concilio optó por una renovación que nacía de una apertura tridimensional, si cabe hablar así. Aunque algunos pensaron que tal apertura redundaría en una claudicación ante las modernas quimeras de la época y en una renuncia a la solidez secular de la doctrina, lo que en realidad se propuso el Concilio «pastoral», audazmente convocado por Juan XXIII y lúcidamente conducido por Pablo VI, fue emprender una labor eminentemente «misionera»:

«La triple apertura que el Concilio reclamó — la apertura a las fuentes, la apertura a las otras confesiones cristianas, la apertura a las cuestiones de toda la humanidad- no es expresión de un deseo de secularización, de una acomodación barata, sino que expresa en el fondo la vuelta al sentido total de la teología, es decir, a su deber misionero. El compromiso misionero exige ante todo el riesgo de la totalidad de

21 GS 1 .

22 Joseph Ratzinger. “¿Iglesia abierta al mundo? Reflexiones sobre la estructura del concilio Vaticano II”. En Obras completas VII/2. Sobre la enseñanza del concilio Vaticano II, 943. Madrid: BAC, 2016. Conferencia pronunciada por primera vez el 23 de junio de 1966, por invitación de la Katholische Hochschulgemeinde de Aquisgrán. 
lo cristiano y, consiguientemente, el riesgo de lo humano, pero no para permanecer estancados en ello, sino para dar a todo lo humano, en Cristo y en su pasión, el sentido divino al que está llamado»²3.

\subsection{A la luZ del Misterio de CRISTO}

El Concilio fijó su mirada en el misterio de Cristo como luz y criterio para discernir todo tiempo mediante la presencia viva de su Espíritu. Sin lugar a dudas, para el cristiano, el amor primero de Dios tiene en Cristo su cifra paradigmática: un amor que abraza al ser humano y su historia allí donde se encuentra, con sus logros y sus heridas, con sus gozos y sus desconsuelos, con sus esperanzas y sus zozobras. Por eso, la contemplación del misterio de la Encarnación urge per se a la Iglesia de cada tiempo a asumir toda cultura y toda historia. En este sentido, la misión eclesial es siempre consecuencia del dinamismo encarnatorio de la misión del Hijo a impulso del Espíritu. El amor de Dios —una vez más- precede al nuestro: Él ha querido ser un Dios-con-nosotros hasta alcanzarnos de modo nunca previsto, «escandaloso» para algunos y «necio» para otros (cf. 1Cor 1,22-23).

No obstante, nuestra mirada cristológica resultaría miope si se detuviera únicamente en el «sí» de Dios a la humanidad, sin atender también al modo en que este "sí» fue pronunciado: el misterio cristológico de la Encarnación no se comprende en su ultimidad sino a través del misterio pascual. No es posible comprender adecuadamente la autodonación de Dios a los hombres sin ponderar el culmen pascual del misterio del Hijo. Por otra parte, nuestra fe atestigua que la misión de Cristo es fuente y culmen de la historia, sin agotar por ello la plenitud del don de Dios: Él nunca se agota en su darse. El «sí» de Dios está movido por su libérrima finalidad de compartir con el hombre su misma vida divina. Por eso, para entender la misión de la Iglesia, se pregunta J. Ratzinger:

23 Ibid., 930-931; si bien, advierte de que «la orientación cristológica del mundo, algo que se desprende claramente de la Escritura, persigue la cristianización de todo; la incorporación de todo en Cristo, Señor de todo, es su último sentido. La orientación eclesial del mundo, por el contrario, no puede tener por objetivo una eclesialización de todo, una eclesialización del mundo y de todas sus realidades» (939). 
«¿Hacia dónde tiende el hecho de la autorrevelación, la autotrascendencia y la mundanización de Dios en Cristo? ¿Quizá pretende sólo confirmar al mundo en su ser mundo y en su mundanidad, haciéndose compañero suyo sin interferencias, dejándolo tal cual es en sí mismo? La pregunta podría parecer retórica, pero haremos bien en no despacharla con excesiva simpleza, pues al acontecimiento de Cristo pertenece lo inesperado: se da en él un commercium, es decir, un intercambio entre Dios y el mundo, y en tal grado que se puede designar como "diálogo". De nuevo, pues, se deja atrás la antigua concepción de mundo, según la cual no hay ningún influjo de lo inferior sobre lo superior, ni ninguna audición de arriba hacia abajo, de tal modo que el intercambio queda aquí necesariamente excluido y suprimido. Pero es claro, a la vez, que este intercambio sería en realidad engañoso si en él se quisiera poner al mundo y a Dios al mismo nivel, y no elevar en última instancia el mundo hasta Dios» ${ }^{24}$.

En su misión, la Iglesia sale de sí misma para comunicar el amor de Dios, de modo que todos puedan participar de su plenitud. «Dios no envió a su Hijo al mundo para condenar al mundo», tampoco para «mundanizarse» o dejarse vencer por el misterio del mal y de la fatalidad, «sino para que el mundo se salve por Él» (Jn 3,17). En su más auténtico quehacer misionero, la teología patrística supo expresarlo de modo admirable al hablar de la theosis: Dios se hizo hombre (Deus capax hominis) para que el hombre participe del ser de Dios (homo capax Dei) ${ }^{25}$. Así se lo recuerda la Iglesia a sí misma cuando afirma:

«La razón más alta de la dignidad humana consiste en la vocación del hombre a la comunión con Dios. El hombre es invitado al diálogo con Dios desde su nacimiento; pues no existe sino porque, creado por Dios por amor, es conservado siempre por amor; y no vive plenamente según la verdad si no reconoce libremente aquel amor y se entrega a su Creador ${ }^{26}$.

24 Ibid., 924-925.

25 Cf. Ireneo de Lyon. Adversus hareses III, 19, 1; Clemente de Alejandría. Pedagogo I, 6, 26; Protréptico I, 8, 4; XI, 114, 4; Orígenes de Alejandría. Contra Celsum III, 28; De principiis II, 6; Atanasio de Alejandría. Adversus arianos I, 39; II, 70; III, 19 y 53; De incarnatione Verbi I, 1 y 54, 3; Gregorio de Nisa. Adversus Apollinarem XI; XV; Juan Crisóstomo. Homilice in Joannem XI, 1; León Magno. Sermón 26, 6; Agustín de Hipona. De Trinitate V, 2, 4; Sermón 166, 4; etc.

26 GS 19a. 


\subsection{El doble anclaje de LA Misión: El MANDATO y LA CAPACITACión}

El amor de Dios manifestado en Cristo nos precede no solo desde el plano cronológico o paradigmático, sino que en su previedad sustenta la respuesta amorosa del hombre. Dicho en otros términos, el hecho de que podamos amar a Dios en retorno de amor es ya en sí mismo un fruto del amor primero de Dios hacia nosotros. Así comprendida, la misión de la Iglesia se arraiga naturalmente en este dinamismo amoroso del Dios-con-nosotros. El suyo es un amor que nos hace dignos, porque nos capacita para el agradecimiento sin humillarnos:

«El Poder si solo se manifiesta como tal es la suprema humillación del hombre. Dios solo se nos desvela como gracia y amor si comparte nuestra debilidad y fragilidad. [...] No se puede ayudar con dignidad a alguien si no se le dan los medios para que el agradecimiento no le sea humillante, no engendre resentimiento y odio. [...] Cristo nos ha dado la posibilidad de agradecer sus dones dejándonos sus signos objetivos para corresponderle: el Evangelio, el Apóstol, el Espíritu Santo y la Comunidad. Estas mediaciones nos son divinamente otorgadas en primer lugar para poder acoger su gracia y en segundo lugar para que nuestro agradecimiento esté a la altura de su Don. Así, comprendida y vivida, la fe no humilla, sino que levanta del suelo a todo hombre capaz de mirar más allá de los bordes de su finitud confiándose al que es su Creador y su Consumador ${ }^{27}$.

En buena lógica, podríamos decir que, así como el amor no es ya una prescripción, sino una respuesta al don otorgado, así también la misión no radica únicamente en el mandato expreso del Señor Jesús (Mt 28,1920), sino también, y más profundamente, en el dinamismo mismo de la existencia cristiana. El envío misionero de los discípulos es inclusión en la vida de Dios, en su modo de darse y, por esto mismo, participación en la apertura de Dios al mundo. Como bien señala Y. Congar, en el decreto Ad gentes divinitus, se habla del envío de los discípulos de Cristo a un doble nivel: por una parte, porque pertenecen a una Iglesia que ha recibido un mandato formal de misión; por otra, porque su vida — fe, caridad, incorporación al Cuerpo místico, presencia del Espíritu Santo-los

27 Olegario González de Cardedal. "Poder y ternura”. En $A B C$ (23/12/2018): 3; por eso, el texto comienza afirmando que «si en el inicio está Belén en el final está la cruz: uno y otro son los signos identificadores de Dios con nosotros. El Absoluto manifestado en su absolutez es incomprensible e inaccesible para el hombre». 
incluye en una responsabilidad y los impulsa por su dinamismo interior a dar testimonio del Evangelio y a dilatar el Cuerpo de Cristo en nuevas vidas personales y en nuevos espacios humanos ${ }^{28}$. O como bien explica J. Ratzinger:

«El hecho de darse aquí un intercambio, el hecho de que Dios toma lo nuestro para así darnos lo suyo, y no para otra cosa, es un gesto de nobleza que acepta la pobreza del mendigo como su propia riqueza para hacer soportable el regalo de la riqueza, un regalo al que él, en última instancia, no puede corresponder con nada. Este dato se hace especialmente patente si recordamos que la teología, en conexión con la Escritura, ha descrito la apertura de Dios al mundo en Cristo con el concepto de "envío" (missio). Su sentido es la impregnación del mundo con la Palabra de Dios y, de este modo, su transfiguración en la unidad del amor con Dios en su interior ${ }^{29}$.

Estas consideraciones que pueden parecer meramente especulativas trasparentan, sin embargo, la entidad y consistencia de la vocación misionera de la Iglesia. En sí misma, ella no tiene un ser y una capacidad de significación propios ${ }^{30}$. Su misión no es paralela a la de Cristo. Antes bien, la Iglesia se sabe «sacramento, esto es, signo e instrumento» ${ }^{31}$ de la apertura de Dios en Jesucristo:

«No hay para la Iglesia posibilidad alguna de encerrarse en sí misma, satisfecha de lo conseguido. Ella misma es el gesto de apertura, y por eso tiene que ponerse constantemente al servicio de este gesto y llevarlo a cabo históricamente. Pero este gesto no tiene en modo alguno una finalidad en sí mismo, sino que su objetivo único es el de introducir en el sacrum commercium, en el sagrado intercambio que ha comenzado

28 Cf. Yves Congar. "Principes doctrinaux". En Vatican II. L'activité missionnaire de l'Église. Décret "Ad gentes», dirigido por Johannes Schütte, 196. Paris: Cerf, 1967.

29 Ratzinger, 925.

30 K. Barth hace hincapié en esto mismo apelando a la apostolicidad de la Iglesia: «En tant qu'elle est apostolique, l'Église ne peut jamais ni sous aucun prétexte devenir un but en elle-même ; à l'exemple des apôtres, elle n'existe elle aussi qu'en exerçant son ministère de héraut. [...] La communauté de Jésus-Christ ne peut donc jamais être, si peu que ce soit, satisfaite d'elle-même, de ce qu'il lui est donné d'être et de faire. [...] Sa mission n'est pas une seconde chose à côté de son être ; mais l'Église est parce qu'elle est envoyée et qu'elle est active en vertu de sa mission. C'est à cause et en vue de sa mission qu'elle s'édifie» (Karl Barth. Dogmatique. Vol. IV/1, t. 3. Genève: Labor et Fides, 1967, 90-91 [§ 62.2]).

31 Cf. LG I, 1. 
con la encarnación de Dios. Por consiguiente, sólo hay legítimamente una doble forma de apertura de la Iglesia al mundo y, por supuesto, tiene que darse siempre: la misión como realización conjunta del movimiento del envío, y el simple gesto del amor desinteresado y servicial en el cumplimiento del amor de Dios que se derrama. Incluso allá donde no encuentra respuesta» ${ }^{32}$.

\subsection{LA NATURALEZA MISIONERA DE LA IGLESIA}

En este sentido, se ha acuñado con razón la expresión Ecclesia de Trinitate, para comprender a la Iglesia dentro de todo el conjunto orgánico del misterio cristiano, cuyo fin no es otro que el de «nuestra participación, por la gracia de Cristo, en la vida interna de Dios» ${ }^{33}$. No en vano, la Iglesia - sin confundir su naturaleza con la de Dios-forma parte de los artículos de la fe profesados en el Símbolo, y forma parte del designio salvador de Dios en la historia ${ }^{34}$. Contemplada desde la perspectiva trinitaria, la Iglesia manifiesta un triple exceso: «es donación del Padre (por su designio eterno), permanece arraigada en el Hijo (en su forma histórica redimida pero necesitada de conversión) y camina vivificada por el Espíritu (hacia su destino escatológico)». Y contemplada desde el despliegue de la historia de la salvación, «la Iglesia se presenta como el gran valle que el Espíritu traza entre dos cumbres excesivas: la del Calvario y la de la Jerusalén celeste». Así, puede decirse que «la comunidad eclesial es prolongación de la sobreabundancia del amor de Dios en Cristo incoado en la historia y, a la vez, anticipación de la sobreabundancia del amor de Dios en Cristo consumado en el éschaton». O que "la Iglesia recibe y continúa la obra del Hijo humanado, al tiempo que pregusta y prefigura la obra del Señor de la Gloria» ${ }^{35}$.

32 Ratzinger, 925 (subrayado nuestro).

33 Henri de Lubac. "Ecclesia de Trinitate". En Las Iglesias particulares en la Iglesia universal, 195. Salamanca: Sígueme, 1974.

34 Cf. Íd. Meditación sobre la Iglesia. 2. a ed. Madrid: Encuentro, 2011, 51-61; Íd. La fe cristiana. Ensayo sobre la estructura del Símbolo de los Apóstoles. 2. ${ }^{a}$ ed. Salamanca: Secretariado Trinitario, 2012, 138-139; Íd. “Credo Ecclesiam”. En Sentire Ecclesiam. Das Bewusstsein von der Kirche als gestaltende Kraft der Frömmigkeit. Festschrift für H. Rahner, dirigido por Jean Daniélou y Herbert Vorgrimler, 13-16. Freiburg im Breisgau: Herder, 1961.

35 Adrián de Prado Postigo. Con infinito exceso. La fe cristiana a la luz de un Amor sobreabundante. Santander: Sal Terrae, 2016, 344. 
Así las cosas, podemos advertir en qué medida un renovado concepto de misión ayudó a los padres conciliares a expresar la naturaleza del misterio eclesial en la Constitución dogmática sobre la Iglesia y en el decreto Ad gentes divinitus, que desarrolla y concreta la doctrina de Lumen gentium. Comunión y misión constituyen el corazón del misterio de Dios Trino y de su proyecto de salvación, de suerte que la Iglesia puede - y debe-comprenderse a sí misma desde ellos. Por esta razón, «el Concilio ha relacionado paralelamente el misterio de la Iglesia como comunión y el misterio de la Iglesia como misión con el Padre, el Hijo y el Espíritu Santo», de suerte que, si en la Trinidad está «la fuente y el paradigma» de la unidad eclesial, «en la autocomunicación de Dios está su impulso misionero» ${ }^{36}$. Los textos conciliares han querido recuperar así una eclesiología de perfil alto, acudiendo a las fuentes de la Escritura y de la tradición patrística, y recordar a la Iglesia su arraigo trinitario ${ }^{37}$. Este le permitirá a la comunidad creyente tomar conciencia del modo en que Dios ha mostrado su amor al mundo, especialmente a lo perdido y alejado, para que su misión sea llevada a cabo en consecuencia y continuidad ${ }^{38}$.

Son muchos los teólogos que hacen uso de la expresión missio Dei para repensar la actividad misionera desde sus bases teológicas y afirmar que la Iglesia no «tiene» una misión propia, sino que participa de la única misión de $\operatorname{Dios}^{39}$. Sin recurrir necesariamente a dicho concepto, la

36 Cf. Ricardo Blázquez. "La Iglesia es por naturaleza misionera". En La Iglesia. Misterio, comunión, misión. Salamanca: Sígueme, 2017, 85; Severino Dianich. Iglesia en misión. Hacia una eclesiología dinámica. Salamanca: Sígueme, 1988; AA 2: «La vocación cristiana, por su misma naturaleza, es vocación al apostolado». Como bien explica S. Madrigal, la teología conciliar nos ofrece una rica fundamentación misionera del misterio de la Iglesia a partir de la idea paulina del «cuerpo de Cristo», entendida en clave misionera, más que ontológica (cf. Santiago Madrigal. Iglesia es Caritas. La eclesiología teológica de Joseph Ratzinger - Benedicto XVI. Santander: Sal Terrae, 2008, 205); Íd. "La actividad misionera de la Iglesia, ad gentes divinitus missa ut sit sacramentum salutis universale". En El Concilio Vaticano II. Una perspectiva teológica, dirigido por Vicente Vide y José Ramón Villar, 355-398. Madrid: San Pablo, 2013; Íd. "La dimensión misionera: del Vaticano II a la nueva evangelización". En El giro eclesiológico en la recepción del Vaticano II. Santander: Sal Terrae, 2017, 259-294.

37 Cf. LG I, 2-4; AG 2-4.

38 Cf. Blázquez, 86.

39 Si bien el concepto hunde sus raíces en la teología de K. Barth, E. Brunner y R. Niebuhr, la fórmula missio Dei fue acuñada en la reflexión llevada a cabo dentro de la Iglesia presbiteriana de EE. UU. por una nueva generación de teólogos y se fue extendiendo hasta lograr una amplia acogida en el movimiento ecuménico universal; 
teología trinitaria ha sabido explicar cómo el dinamismo misionero tiene su fundamento en las procesiones divinas y deriva de las dos únicas e inseparables misiones trinitarias: la del Hijo y la del Espíritu. «La Iglesia peregrinante es, por su propia naturaleza, misionera, puesto que tiene su origen en la misión del Hijo y la misión del Espíritu Santo según el plan de Dios Padre ${ }^{40}$. La misión —como acuñará Y. Congar- es «una en sí misma; es, en definitiva, coextensiva a la existencia misma de la Iglesia ${ }^{41}$. Propiamente hablando, podría decirse que no existe otra misión que la del Hijo —incluyendo en ella el don del Espíritu—42. La misión arranca, pues, del corazón de la Trinidad y la dimensión misionera de la Iglesia es «el signo sacramental de la gracia preveniente de Dios que va delante de los hombres porque Él los ama primero ${ }^{43}$. Desde el comienzo de su pontificado, el papa Francisco nos recuerda insistentemente cómo esta

cf. Jacques Rossel. “'From a Theology of Crisis to a Theology of Revolution?'. Karl Barth, Mission and Missions. The Ecumenical Review 21, n. 3 (1969): 204-215; H. H. Rosin. "Missio Dei»: An Examination of the Origin, Contents, and Function of the Term in Protestant Missiological Discussion. Leiden: Interuniversity Institute for Missiological and Ecumenical Research Department of Missiology, 1972; Wilhelm Richebächer. "Missio Dei: The Basis of Mission Theology or a Wrong Path?”. International Review of Mission 92, n. ${ }^{\circ} 4$ (2003): 588-605; Philip Lauri Wickeri. "Mission from the Margins. The Missio Dei in the Crisis of World Christianity". International Review of Mission 93, n. ${ }^{\circ} 2$ (2004): 182-198.

40 AG 2a; cf. Congar, 187-188: «La théologie des missions divines fonde l'existence même de l'Église : elle ne fonde pas spécifiquement une activité missionnaire, ou bien il faudrait dire que tout ce que fait et est l'Église, est missionnaire, et l'on perdrait la précision de la notion. Dira-t-on que l'Église est missionnaire au ciel, alors qu'elle y est plus purement elle-même, par la communication qui lui est faite des divines Personnes ? Notons d'abord qu'on parle de l'Église en son état d'itinérance : c'est d'elle dont on dit qu'elle est toute missionnaire».

41 Cf. Congar, 198.

42 Cf. Jean Daniélou. "La misión del Verbo". En Trilogía de la salvación, Madrid: Guadarrama, 1964, 313-328: «De acuerdo con el mandato de Nuestro Señor: "De la misma manera que el Padre me envió, os envío yo a vosotros" (Jn 20,21), la vida misionera es como un prolongamiento de esta misión del Hijo al mundo, enviado por el Padre. Como primera misión, representa el punto de partida, el origen único, la raíz de cualquiera otra misión posterior. En realidad, no hay más que una misión propiamente dicha, y es esta; todas las demás no son más que participación o derivación suya» (313).

43 Cf. Marie-Joseph Le Guillou. "La vocación misionera de la Iglesia". En La Iglesia del Vaticano II. Estudios en torno a la Constitución conciliar sobre la Iglesia,

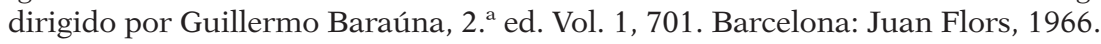


iniciativa divina que nos precede y "primerea» ha de movernos a comprender nuestra misión y, por eso mismo, a integrarla como parte esencial de nuestra vida espiritual:

«La Iglesia en salida es la comunidad de discípulos misioneros que primerean, que se involucran, que acompañan, que fructifican y festejan. [...] La comunidad evangelizadora experimenta que el Señor tomó la iniciativa, la ha primereado en el amor (cf. 1Jn 4,10); y, por eso, ella sabe adelantarse, tomar la iniciativa sin miedo, salir al encuentro, buscar a los lejanos y llegar a los cruces de los caminos para invitar a los excluidos. Vive un deseo inagotable de brindar misericordia, fruto de haber experimentado la infinita misericordia del Padre y su fuerza difusiva. ¡Atrevámonos un poco más a primerear!»4${ }^{44}$.

«La Iglesia peregrinante es, por su propia naturaleza, misionera ${ }^{45}$, sin otra finalidad que la de que todos los hombres y pueblos lleguen a experimentar el amor misericordioso del Padre y así "participar plenamente en el misterio de Cristo ${ }^{46}$. En realidad, todo cuanto la Iglesia vive y lleva a cabo consiste propiamente en incorporar a todos los hombres en la comunión con Jesucristo:

«Cristo como cabeza de la Iglesia continúa a través de ella la misión encomendada por el Padre. Ella es sacramento de Cristo, donde el sujeto principal de la misión sigue siendo Cristo mismo. Él es quien se hace presente a través de la misión de la Iglesia, que, en cuanto comunión (koinonía), despliega su ser en tres dimensiones fundamentales: la leiturgía y la acción sacramental, la martyría o el anuncio del evangelio y la diakonía o el servicio de la caridad» ${ }^{47}$.

44 Francisco. Evangelii gaudium, n. 24; cf. también, n. 12 («en cualquier forma de evangelización el primado es siempre de Dios, que quiso llamarnos a colaborar con Él e impulsarnos con la fuerza de su Espíritu»); n. 112 («el principio de la primacía de la gracia debe ser un faro que alumbre permanentemente nuestras reflexiones sobre la evangelización»); n. 162 («este camino de respuesta y de crecimiento está siempre precedido por el don, porque lo antecede aquel otro pedido del Señor: "bautizándolos en el nombre..." [Mt 28,19]»).

45 AG 2.

46 AG 5a; cf. Congar, 194-195: «Tout n'est-il pas compris dans la définition qui termine le premier alinéa du n. ${ }^{\circ}$ 5: "vers une pleine participation au mystère du Christ" ?".

47 Ángel Cordovilla. Crisis de Dios y crisis de fe. Volver a lo esencial. Santander: Sal Terrae, 2012, 141; cf. Benedicto XVI. Deus caritas est, n. 25; Santiago Madrigal. Iglesia es Caritas. La eclesiología teológica de Joseph Ratzinger - Benedicto XVI. Santander: Sal Terrae, 2008. 
No podemos pensar la comunión y la misión en alternativa; una y otra se implican mutuamente. Si la Iglesia no partiera del amor experimentado en la comunión con Dios, de la vida que recibe de Él, su misión no sería más que un buscarse a sí misma, a través de las más diversas actividades que pudiera llevar a cabo. Asimismo, la Iglesia tampoco llegaría a descubrir la sobreabundancia de la comunión con Dios si no asumiera la misión como modo concreto de acoger y vivir el amor misionero de Dios. A fin de cuentas, la misión que la Iglesia lleva a cabo no es sino la comunión misma celebrada y actualizada, proclamada y humildemente transmitida:

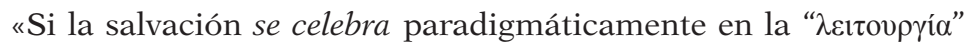

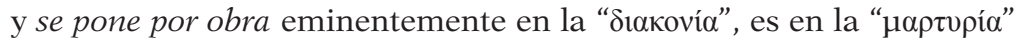
donde se transmite la sobreabundancia de esta Buena Nueva. Aunque sabemos que el anuncio de la salvación está estrechamente relacionado con los orígenes de la Iglesia y con su misma esencia, puede llamar la atención que la comunidad eclesial, que ya celebra la salvación en los ritos y la actualiza continuamente en las obras, necesite proclamarla expresamente por medio de la palabra evangelizadora. [...] En realidad, los convocados en Cristo son sacramento que escucha y que habla, que recibe y que dona. La razón es muy simple: la Iglesia no hospeda en su seno un don monolítico ni perpetúa a lo largo del tiempo una herencia fosilizada. Muy al contrario, ella acoge una gracia personal llena de matices (la Vida en Cristo) y da a conocer sin descanso una "tradición viva" (DV 12). Lo que la comunidad creyente experimenta en su dimensión martirial o kerygmática es, por tanto, un diálogo de amor ininterrumpido - entre Dios y la Iglesia, entre la Iglesia y el mundo- en el que ella es a la vez la oyente de la palabra y su pregonera ${ }^{48}$.

En el misterio de la Iglesia contemplamos hasta qué punto Dios ha querido ser un «Dios-con-nosotros» que nos capacita para recibir el don de su amor en libre reciprocidad, actualizándolo y anunciándolo en un eterno presente. De esta manera, la Iglesia descubre que solo desempeñando su dinamismo misionero puede cumplir su vocación y acoger en plenitud el don divino que la constituye. Ahora bien, una condición se impone para que esto sea así: la misión ha de desarrollarse en el mismo modo en que Cristo la ejerció, recorriendo su mismo camino a la hora de anunciar, inaugurar y cumplir el Evangelio ${ }^{49}$. Un camino que, como

\footnotetext{
48 Prado Postigo. Con infinito exceso, 381.

49 Cf. Cordovilla. Crisis de Dios y crisis de fe, 141: «La misión es del Hijo y desde él, de toda la Iglesia. Él es el sujeto protagonista de la misión y el modelo de la forma 
nos enseña el magisterio, abraza la pobreza, la obediencia, el servicio y la renuncia a uno mismo:

«Como esta misión continúa y desarrolla en el curso de la historia la misión del propio Cristo, que fue enviado a evangelizar a los pobres, la Iglesia, impulsada por el Espíritu Santo, debe avanzar por el mismo camino por el que avanzó Cristo: esto es, el camino de la pobreza, la obediencia, el servicio y la inmolación de sí mismo hasta la muerte, de la que surgió victorioso por su resurrección ${ }^{50}$.

\section{ALGUNAS PERSPECTIVAS DE UNA ESPIRITUALIDAD MISIONERA}

Antes de desarrollar algunas perspectivas de una espiritualidad para la misión, estamos ya en condiciones de preguntarnos si de verdad existe una «espiritualidad misionera», o si, por el contrario, dicha expresión no es más que un juego de palabras, deudor de las modas de nuestro tiempo. En sentido estricto, lo misionero no puede ser un añadido a la espiritualidad o a los carismas, como si adornáramos algo sustantivo - la espiritualidad-con algo adjetivo y, por ende, prescindible - lo misioneroLa espiritualidad es siempre y per se misionera, así como la misión es siempre y per se espiritual ${ }^{51}$. Si explicitamos que la nuestra ha de ser siempre una espiritualidad para la misión es para no olvidar esta peculiaridad

concreta de su realización. Todos los creyentes en la práctica de su vida cristiana están ejerciendo un ministerio que nace de su incorporación al cuerpo de Cristo por el bautismo y se despliega en el ejercicio del ser sacerdotal, profético y real».

50 AG 5b (subrayado nuestro); cf. Congar, 197-198: «le mode qui convient à l'exercice de la mission de l'Église : dans la continuité et à l'exemple du Christ ("sequentia sancti Evangelii ”!), l'Église doit suivre, dans l'exercice de sa mission, une voie de descente vers les hommes et leur pauvreté. Le " qui propter nos homines et propter nostram salutem, descendit... ” vaut pour elle comme il vaut pour le Christ. C'est la voie de kénose dont parle Ph. 2,5-11, c'est la voie pascale : à la vie par la mort, à la gloire par l'humiliation».

51 Una excelente reflexión sobre la profunda unidad de la espiritualidad y la misión en el magisterio reciente, en: Gabino Uríbarri. Santidad misionera. Fuentes, marco y contenido de Gaudete et exsultate. Santander: Sal Terrae, 2019. A lo largo del libro, el autor explica cómo — con el pontificado de Francisco y su programa teológico-pastoral— la Iglesia ha entrado en una nueva fase de recepción del Concilio Vaticano II, caracterizada por la correlación sustancial entre la espiritualidad-santidad y la misión-evangelización. 
hermosísima y retadora de nuestra fe: desde el punto de vista cristiano, la vida espiritual no sería auténtica si no se dejase moldear por el modo misionero en que Dios se nos llega, y la misión no será cristiana si no nace de la experiencia vivida de la gracia de Dios. Así pues, la relación intrínseca entre ambas constituye para la Iglesia de todos los tiempos una clave de discernimiento en fidelidad viva a nuestra vocación bautismal.

El modo de la misión en cuanto camino de renuncia, servicio, pobreza y obediencia, tal como el Concilio nos enseña, conecta de forma natural con el triple dinamismo carismático que la Iglesia experimenta a través de la vida religiosa. La renuncia a uno mismo que mira a la disponibilidad para Dios y su Evangelio, o el servicio vocacionado al que se consagran los religiosos, son concretados desde la triple perspectiva de la pobreza, la castidad y la obediencia, y conforman un indiscutible don de Dios para la vida de la Iglesia. Al relacionar la espiritualidad y la misión con los consejos evangélicos no pretendemos describir exclusivamente la vida de especial consagración. Más bien, quisiéramos presentar una realidad que concierne a todo cristiano. Nuestra propuesta es acercarnos a la pobreza, la castidad y la obediencia en cuanto rasgos descriptivos de la humanidad de Cristo, de su fe y entrega en cuanto vividas:

«Estas palabras —obediencia, pobreza, castidad-, que a lo largo de la historia de la espiritualidad han adquirido tantos significados diferentes, en realidad expresan la singular humanidad de Jesús de Nazaret, la singular humanidad del Hijo de Dios y, por tanto, la modalidad con la que Cristo nos asimila a Sí, nos conforma a su humanidad $»^{52}$.

Si ligamos la espiritualidad misionera a los votos es porque la vida de Jesús en su relación con el Padre fue esencialmente misionera. Y esta existencia misionera del Hijo, la Iglesia la ha condensado en torno a tres realidades fundantes o tres puntos de gravitación propios del radicalismo evangélico de Jesús. Así nos lo recuerda el magisterio: la pobreza, la obediencia y la castidad son "expresión privilegiada» para todos los cristianos, sin excepciones, de la radicalidad con la que Jesús llama al seguimiento y a la comunión de vida en el Espíritu ${ }^{53}$. Por consiguiente, cabe acercarse a cada uno de esos lugares existenciales de la vida del Hijo

52 Paolo Martinelli. Seguir hoy a Cristo. Vida sacerdotal y consejos evangélicos. Madrid: Encuentro, 2018, 16-17.

53 Cf. Juan Pablo II. Pastores dabo vobis, n. 27. 
para mostrar algunos de los rasgos más notorios de la espiritualidad que brota de la vida bautismal.

Hemos comenzado describiendo la espiritualidad como la fe misma en cuanto vivida, es decir, el proceso relacional y biográfico entre el hombre y Dios sostenido en la fe y la entrega. Si esto es así, al trasluz de una mirada trinitaria también podríamos comprender la espiritualidad como comunión en la vida de Dios y la misión como participación en el don por Él otorgado. Una y otra vendrían a ser las dos caras de la misma moneda, el doble movimiento de sístole y diástole del latir amoroso que une al hombre con la vida de Dios ${ }^{54}$.

Miremos, entonces, nuestra espiritualidad sabiendo que lo misionero forma parte de su entraña. Y, al mismo tiempo, consideremos nuestra misión sabiendo que la espiritualidad es su razón última de ser. De este modo, podremos trazar los perfiles de una auténtica espiritualidad para la misión apoyándonos en los fundamentos teológicos de la espiritualidad, señalados al comienzo, y en los fundamentos teológicos de la misión, que acabamos de explicar. Singularmente, tendremos en cuenta, por un lado, la intuición balthasariana de la espiritualidad como triple movimiento del ser humano en cuanto espíritu y, por otro, el modo concreto de la misión según la vivió Jesús, en castidad, pobreza y obediencia. Bien mirado, la espiritualidad y la misión convergen en los consejos evangélicos, no solo para nosotros, los consagrados, sino para todo cristiano. Al ser un reflejo explícito del modo de vida de Jesús —en comunión con Dios y en misión hacia los hombres- la pobreza, la obediencia y la castidad resumen de modo paradigmático los dinamismos esenciales de lo que entendemos por una espiritualidad misionera. En los tres apartados que siguen y de la mano de cada uno de los tres votos, intentaremos articular las implicaciones espirituales de la vida como misión, desgranando los rasgos más significativos desde la vertiente más espiritual (a) y desde la vertiente más misionera (b).

No se trata de establecer una correlación estricta y exclusiva entre cada voto y algunos aspectos de la misión, sino más bien de mostrar las posibilidades que nos permite desplegar la vida de especial consagración.

54 Cf. Jesús Castellano Cervera. "Spiritualità e missione alla luce della Esortazione apostolica 'Vita consecrata”. En Spiritualità e missione. Il "proprium» della vita religiosa alla luce della Esortazione postsinodale "Vita consecrata», dirigido por Conferenza Italiana dei Superiori Maggiori, 39-74 (esp. 39-43). Roma: Rogate, 1997. 
Así, en el voto de pobreza se hace patente la búsqueda y el deseo de Dios en la vida del hombre, que es capaz de ir renunciando a sí mismo con la esperanza de hacer de Dios su mayor riqueza y de abrazar el modo de vida proexistente de Jesús. En el voto de castidad podemos percibir la fecundidad propia de un amor audaz, capaz de tomar decisiones y emprender acciones que lo llevan a salir de sí y a vivir una verdadera conversión al Evangelio desde la lógica de la entrega. Finalmente, el voto de obediencia es cifra de la disponibilidad a acoger la voluntad de Dios y a configurar la propia existencia a imagen de la fidelidad filial de Cristo enviado.

\subsection{LA POBREZA COMO CRECIMIENTO}

Si una de las dimensiones elementales de toda espiritualidad es la búsqueda de Dios y el deseo de su presencia, entonces un aspecto de la espiritualidad misionera ha de ser esa salida de uno mismo con la esperanza de poder acoger la incomprensibilidad de la vida y encontrar a Dios allí donde y como Él se halla. En efecto, dicha búsqueda está sostenida en la esperanza y nos abre a un nuevo horizonte hacia el que recorrer un auténtico proceso de crecimiento, desposesión y profundización que nos permita trascender la inmanencia de nuestra finitud.

\section{a) Testigos de una búsqueda: la esperanza}

En primer lugar, la pobreza es, para una espiritualidad misionera, una llamada a la esperanza. Esperanza de poder y querer buscar al Dios que se deja encontrar. Aunque suene paradójico, caminamos misioneramente hacia dentro de nosotros mismos, viviéndonos ante Dios (coram Deo), buscando su presencia. Como tantas veces expresamos con el Salmo: "Oigo en mi corazón: "Buscad mi rostro". Tu rostro buscaré, Señor; no me escondas tu rostro» (Sal 26,8-9). En este sentido, la vida de especial consagración es testimonio para el mundo de toda una veta de búsqueda de Dios, como recordaba no hace tanto tiempo el papa Benedicto XVI:

«Por vocación sois buscadores de Dios. A esta búsqueda consagráis las mejores energías de vuestra vida. Pasáis de las cosas secundarias 
a las esenciales, a lo que es verdaderamente importante; buscáis lo definitivo, buscáis a Dios, mantenéis la mirada dirigida hacia él. Como los primeros monjes, cultiváis una orientación escatológica: detrás de lo provisional buscáis lo que permanece, lo que no pasa. Buscáis a Dios en los hermanos que os ha dado, con los cuales compartís la misma vida y misión. Lo buscáis en los hombres y en las mujeres de nuestro tiempo, a los que sois enviados para ofrecerles, con la vida y la palabra, el don del Evangelio. Lo buscáis particularmente en los pobres, primeros destinatarios de la Buena Noticia (cf. Lc 4,18). Lo buscáis en la Iglesia, donde el Señor se hace presente, sobre todo en la Eucaristía y en los demás sacramentos, y en su Palabra, que es camino primordial para la búsqueda de Dios, nos introduce en el coloquio con él y nos revela su verdadero rostro. ¡Sed siempre buscadores y testigos apasionados de Dios! ${ }^{55}$.

Se trata de trascender las circunstancias de la vida sin huir de ellas, para buscar lo que permanece, lo definitivo, los signos escatológicos de su presencia en nuestro mundo. La búsqueda apasionada de Dios pertenece a la entraña de nuestra vocación, guiada siempre por la luz de su Palabra, y nos invita continuamente a introducirnos en ese diálogo existencial personalísimo que va tejiendo nuestra biografía. Como nos enseña un gran maestro de la búsqueda divina:

«iBusquemos al que ha de ser encontrado; busquemos al que hemos encontrado! Para que busquemos al que ha de ser encontrado, está oculto; para que busquemos al que ha sido hallado, es inmenso. [...] Sacia al que lo busca, según lo que este es capaz; y al que lo encuentra lo hace más capaz, para que, cuando haya comenzado a ser capaz de contener más, de nuevo busque ser colmado» ${ }^{56}$.

En última instancia — diría Agustín— aun cuando lo hayamos encontrado, Dios siempre seguirá siendo el buscado: «Buscad siempre su rostro: que el encontrar no implique el final de la búsqueda, que es característica del amor; sino que el amor creciente aumente también la búsqueda del que ha sido encontrado ${ }^{57}$. La espiritualidad misionera vive en esta inquietud apasionada por Dios, fundamento de nuestra vida.

55 Benedicto XVI. Discurso a los superiores y superioras generales (26/11/2010), §2.

56 Agustín de Hipona. In Joannis evangelium tractatus 63, 1.

57 Íd. Enarrationes in Psalmos 104, 3. 


\section{b) En «proexistencia»: misión y crecimiento}

En segundo lugar, la pobreza es, para una espiritualidad misionera, una llamada a la proexistencia. Nos lleva a vivir desde la menesterosidad de nuestro ser para descubrir aquella perla por la que merece la pena venderlo todo. Esta pobreza no es sino el dinamismo que abre nuestra existencia a la disponibilidad total para con Dios y su gracia, verdadero tesoro de nuestra vida. Al mismo tiempo, la pobreza nos hace descubrir en primera persona una doble riqueza que encierra la misión: por una parte, la salida de uno mismo (ad extra), el aprender a «ser-para» - la propia desposesión - acrecienta la disponibilidad a la hora de tomar parte activa en la misión; por otra, la pobreza evangélica nos sumerge interiormente (ad intra) en un proceso de crecimiento personal. En otras palabras, la misión se convierte en posibilidad de participación en la obra de Dios — «tomar parte en los duros trabajos del Evangelio» (2Tim 1,8a)-y, al mismo tiempo, nos configura por dentro al hacer efectiva en la propia vida la gracia del Señor — «según la fuerza de Dios» (2Tim 1,8b), según «el don de Dios» que hay en nosotros (cf. 2Tim 1,6)—.

De una manera más técnica se suele emplear el término «proexistencia» para expresar el modo de vivir de Jesús en relación con el Padre (dimensión vertical) y en relación con el Reino y sus destinatarios (dimensión horizontal $)^{58}$. Dicha proexistencia - este ser-para- da cuenta de la profunda unidad con la que Jesús vivió lo que nosotros distinguimos como «espiritualidad» y como «misión». Si ampliamos la mirada, descubriremos cómo la proexistencia de Jesús está arraigada en el mismo ser de Dios. La teología trinitaria nos dice que, en el fondo, cada Persona es su misión. Las «misiones» (ad extra) no son simplemente un efecto (entre otros posibles) de las «procesiones» (ad intra), sino que son las procesiones mismas en su realización histórica. Es decir, que el envío del Hijo por el Padre, y del Espíritu por el Padre y el Hijo, es la realización en el seno de la historia de las relaciones propias de la Trinidad en sí misma.

Por teórico y abstracto que pudiera parecer, esto nos permite pensar fecundamente nuestra espiritualidad misionera. La misión no es un mero

58 Cf. Heinz Schürmann. El destino de Jesús: su vida y su muerte, Salamanca: Sígueme, 2003; Joachim Jeremias. ABBÁ. El mensaje central del Nuevo Testamento. 5. ${ }^{a}$ ed. Salamanca: Sígueme, 1999; Walter Kasper. Jesús, el Cristo. Salamanca: Sígueme, 1976. 
efecto (entre otros muchos) de nuestra relación vital con Dios, sino la realización histórica, el despliegue existencial de nuestra vida espiritual. Toda espiritualidad auténticamente cristiana conduce de forma natural a la misión, y viceversa, toda verdadera misión es realización existencial de la espiritualidad. Reiterando la invitación de Juan Pablo II, el papa Francisco no deja de invitar a la Iglesia a redescubrir esta mutua implicación de la espiritualidad misionera cuando nos urge a un "renovado compromiso misionero", convencido de que la misión "renueva la Iglesia, refuerza la fe y la identidad cristiana, da nuevo entusiasmo y nuevas motivaciones"». Porque, "ila fe se fortalece dándola!» ${ }^{59}$.

\subsection{LA CASTIDAD COMO FECUNDIDAD}

La segunda dimensión de la vida espiritual, según la intuición de Balthasar, tiene que ver con la decisión y la acción. Al espíritu humano le resulta altamente difícil persistir en una constante búsqueda indefinida e incierta, a no ser que su inquieta esperanza se concrete en decisiones que realicen y plasmen en la práctica su relación con Dios. La vida espiritual no subsiste únicamente en el deseo, sino que necesita acompasar este deseo con acciones afines al mismo. De lo contrario, corremos el riesgo de disociar de modo insoportable las aspiraciones profundas y su concreción biográfica. La fe cristiana no profesa un ideal ajeno al alcance del hombre (cf. Dt 30,11-14; Rom 10,6-8); antes bien, apoyada en la primacía del amor de Dios, ella acredita que la gracia va capacitando de modo concreto nuestra propia vida para asumirla, purificarla y elevarla. Por esta razón, aun cuando esté hondamente ligada a la interioridad, la espiritualidad no puede quedar circunscrita al ámbito de lo íntimo.

En este orden de cosas, el consejo evangélico de la castidad nos capacita para un amor a imagen del de Jesucristo, en quien deseo y praxis caminaron siempre de la mano: un amor audaz, decidido, sacrificado, generoso y redentor. El amor no es un puro sentimiento, sino la respuesta evangélica a la caridad divina desde la lógica de la entrega. El dinamismo del voto de castidad «representa una especial configuración con el estilo

59 Francisco. Carta con ocasión del centenario de la promulgación de la Carta apostólica «Maximum illud» sobre la actividad desarrollada por los misioneros en el mundo (22/10/17), §3; cf. Juan Pablo II. Redemptoris missio, n. 1. 
de vida del propio Cristo», porque "dicha opción es ante todo esponsal; es una identificación con el corazón de Cristo Esposo que da la vida por su Esposa ${ }^{60}$. En este sentido, la dimensión esponsal de la vida de Jesús pertenece tanto a la forma de su fe vivida como a su misión, ya que muestra el carácter totalizador del amor que se inscribe en nuestra carne ${ }^{61}$.

\section{a) Con audacia evangélica: la caridad}

En primer lugar, la castidad es, para una espiritualidad misionera, una llamada a la caridad valiente: «En esto consiste el amor: no en que nosotros hayamos amado a Dios, sino en que Él nos amó y nos envió a su Hijo» (1Jn 4,10). Ahora bien, siendo este el punto de partida, el hecho de que Dios nos preceda con su amor excesivo no anula nuestra capacidad de respuesta, al contrario: la capacita como retorno de amor. Con el don sobreabundante de sí mismo, Dios nos ama y nos engrandece hasta el punto de posibilitar nuestra libre reciprocidad ${ }^{62}$. Nos hace capaces de ofrecer una respuesta auténticamente libre y personal a su amor, ya que por el bautismo somos incorporados a la dignidad de hijos en el Hijo y, por tanto, nos convertimos en amados que entregan libremente su vida como don de sí mismos.

Esta correspondencia entre el don recibido y el don respondido nos permite comprender otro aspecto capital de la misión de Dios en el mundo. Como explica H. U. von Balthasar, «la revelación de Dios no es ningún objeto para mirar, sino que es su propia acción en y para el mundo, la cual puede ser respondida, y así "comprendida", por el mundo mediante su acción ${ }^{63}$. Es decir, que el modo de comprender el don que Dios hace de Sí mismo pasa necesariamente por la acogida de su amor y —al mismo

\footnotetext{
60 Cf. Benedicto XVI. Sacramentum caritatis, n. 24.

61 Cf. Martinelli, 84-85.

62 Cf. Adrián de Prado Postigo. "Gratuidad fundante, libre reciprocidad y fecundidad esforzada”. En De Dios, a quien amar. La lógica del mérito en De diligendo Deo de san Bernardo. Burgos: Monte Carmelo, 2019, 294-298; se trata de articular una adecuada comprensión de la lógica del mérito en perspectiva cristiana que «en nada resta previedad y primacía al amor de Dios, pero que, a la vez y sin salir del espacio generado por Su gracia, concede un peso cabal a la fe operosa del ser humano, que en Cristo trata de responder a Dios con la misma dilección que Él le concede» (295).

63 Hans Urs von Balthasar. Teodramática 1. Prolegómenos. Madrid: Encuentro, 1990, 19.
} 
tiempo- por nuestra respuesta biográfica. Una vez más, espiritualidad y misión se nos revelan en su necesaria correlación. Solo en la medida en que respondamos operosamente al actuar de Dios en el mundo lograremos «comprenderlo» y acogerlo; y viceversa: en tanto que participamos activamente en la misión vamos aquilatando nuestra espiritualidad. Como sostiene cabalmente el teólogo de Lucerna:

«La gloria de Dios que hace su aparición en el mundo y que alcanza su centro en Cristo no es algo estático que se pueda contemplar de modo neutral. Se hace más manifiesta sólo en un compromiso dispuesto a la lucha, con sus victorias y sus derrotas, y reclama un compromiso análogo para que entre en el propio ángulo de mira» ${ }^{64}$.

Nuestra espiritualidad misionera pasa necesariamente por el camino de la acción, con y como Cristo desde la caridad. El amor de Dios acogido en nuestros corazones nos transforma en cristianos evangélicamente audaces: nos permite vivirnos en la confianza de ser hijos (cf. Rom 8,14-17), experimentar la parresía del Hijo y engendrar vida según la fecundidad propia del grano de trigo que muere y da mucho fruto (cf. Jn 12,24). Así pues, toda espiritualidad misionera está llamada a contemplar el misterio del Calvario para descubrir en primera persona la lógica eucarística que hace fecundo nuestro amor.

¿Acaso la Cruz no interpela nuestros modos de concebir y llevar a cabo la misión? En el fondo, para el cristiano no existe más eficacia que la que brota del costado abierto de Cristo. Es la eficacia de la que se nutren los sacramentos y los mártires. Una eficacia difícilmente mensurable desde los parámetros de la pura inmanencia. Una eficacia que no pretende la autoafirmación, sino la generación de nueva vida a partir del don total de sí. En una palabra, es la eficacia de lo sobrenatural, la eficacia de la resurrección como plenitud de vida. La castidad nos muestra cómo toda espiritualidad filial es necesariamente fecunda: conduce de suyo a la radicalidad de la misión, a la audacia de poder pronunciar aquellas palabras con las que Jesús decidió afrontar su destino: «Nadie me quita la vida, sino que yo la entrego libremente» (Jn 10,18). A través de nuestro compromiso y nuestras luchas, la castidad por el reino de Dios tiene mucho que enseñarnos todavía a la hora de vivirnos y desvivirnos.

64 Íd. Teodramática 4. La acción. Madrid: Encuentro, 1995, 16. 


\section{b) En «estado permanente de misión»: la conversión misionera}

En segundo lugar, el dinamismo espiritual de la castidad como amor no posesivo tiene su correlato en la llamada a la conversión continua. La apertura constante de un amor expansivo por naturaleza nos llevará a ensayar nuevas formas de amar. A pesar de que los hechos a veces pudieran sugerirlo, la castidad no es una renuncia para vivir aislado y desentendido. Jesús fue el hombre libre y comprometido por antonomasia: libre en el amor para amar comprometidamente, a imagen del Padre.

De algún modo, nuestro amor ha de insertarse en lo que el papa Francisco denomina un «estado permanente de misión» ${ }^{65}$. Esto quiere decir que la misión no puede reducirse a un simple hacer, a un programa de actividades. Los verdaderos proyectos misioneros eclesiales no han nacido tanto de elaborados planes estratégicos cuanto de una pasión, un ardor y un celo misioneros. La caridad divina, que nos abraza allí donde nuestra pobre humanidad se encuentra, no ha cesado de convertir a personas corrientes en espíritus decididos que pudiesen atender y socorrer a los más desvalidos de todo tiempo y lugar. Al transformar su amor egoísta en un amor casto, Dios ha logrado en ellos que la caridad concreta produzca vida allí donde solo parecía haber miseria.

Si nos atrevemos a emprender un discernimiento audaz desde la castidad, descubriremos cómo el Espíritu sigue demandando a la Iglesia de hoy una decidida conversión misionera. No se trata de palabras pasajeras que surgen al albur de las modas. El discernimiento y la conversión misionera son una de las mejores expresiones de la convocación eclesial: la Iglesia tiene que llegar a ser de modo más trasparente y eficaz en el mundo de hoy lo que ya es en sí misma por gracia y vocación ${ }^{66}$. No se puede disociar la consagración por el reino de Dios de las modalidades

65 Cf. Francisco. Evangelii gaudium, n. 25. Un análisis de los fundamentos teológicos y de algunas perspectivas sistemáticas del pensamiento del papa Francisco referente a la reforma misionera de la Iglesia, en: Carlos María Galli. "La reforma misionera de la Iglesia según el papa Francisco. La eclesiología del pueblo de Dios evangelizador". En La reforma y las reformas en la Iglesia, dirigido por Antonio Spadaro y Carlos María Galli, 51-77. Santander: Sal Terrae, 2016.

${ }_{66}$ Cf. Francisco. Evangelii gaudium, nn. 34-39 («Desde el corazón del Evangelio»); Ángel Cordovilla. "El lugar de la Iglesia en la sociedad". En «Como el Padre me envió, así os envío yo». Teología y espiritualidad del ministerio apostólico presbiteral, Salamanca: Sígueme, 2019, 41-64 (esp., cuando habla de la transformación misionera de la Iglesia [62], vista no como algo meramente externo y estructural, sino con 
concretas en que esta se lleva a cabo. Solo a través de una adecuada conversión misionera lograremos descubrir y vivir en carne propia el don de nosotros mismos a impulso del Espíritu. En este sentido, Francisco es sumamente transparente cuando nos habla de:

«Una opción misionera capaz de transformarlo todo, para que las costumbres, los estilos, los horarios, el lenguaje y toda estructura eclesial se conviertan en un cauce adecuado para la evangelización del mundo actual más que para la autopreservación. La reforma de estructuras que exige la conversión pastoral sólo puede entenderse en este sentido: procurar que todas ellas se vuelvan más misioneras, que la pastoral ordinaria en todas sus instancias sea más expansiva y abierta, que coloque a los agentes pastorales en constante actitud de salida y favorezca así la respuesta positiva de todos aquellos a quienes Jesús convoca a su amistad» ${ }^{67}$.

A la luz del amor que permea toda la vida de Jesús, desde el corazón del Evangelio, hemos de examinar sin miedo si la espiritualidad que vivimos nos mueve a la ofrenda de la propia vida por amor o nos encierra en nuestros apegos e instintos de autopreservación. Necesitamos desengañarnos, también en la clave del amor: o nuestra espiritualidad es misionera, o no será. Las decisiones que vamos tomando y las acciones que vamos realizando van configurando nuestro modo real de ser. A este respecto, el consejo evangélico de la castidad no mutila nuestra dimensión afectiva, carnal y corporal, sino que reorienta nuestro amor según el amor de Cristo. Por eso, hemos de convenir con el papa Francisco que:

«El ideal cristiano siempre invitará a superar la sospecha, la desconfianza permanente, el temor a ser invadidos, las actitudes defensivas que nos impone el mundo actual. Muchos tratan de escapar de los demás hacia la privacidad cómoda o hacia el reducido círculo de los más íntimos, y renuncian al realismo de la dimensión social del Evangelio. Porque, así como algunos quisieran un Cristo puramente espiritual, sin carne y sin cruz, también se pretenden relaciones interpersonales sólo mediadas por aparatos sofisticados, por pantallas y sistemas que se puedan encender y apagar a voluntad. Mientras tanto, el Evangelio nos invita siempre a correr el riesgo del encuentro con el rostro del otro, con su presencia física que interpela, con su dolor y sus reclamos, con su alegría que contagia en

hondas implicaciones personales: «Podremos reformar estructuras, pero la reforma necesita siempre reformadores de su propia vida» [57]).

67 Francisco. Evangelii gaudium, n. 27. 
un constante cuerpo a cuerpo. La verdadera fe en el Hijo de Dios hecho carne es inseparable del don de sí, de la pertenencia a la comunidad, del servicio, de la reconciliación con la carne de los otros. El Hijo de Dios, en su encarnación, nos invitó a la revolución de la ternura» ${ }^{68}$.

Una y otra vez, estamos llamados a volver a las fuentes bautismales de nuestra vocación. Sabemos que la gracia recibida en el sacramento no es automática, sino hacedera, es siempre vida en crecimiento, siempre en camino. Por vocación estamos llamados a ir a más: partiendo del amor de Dios que nos precede y apoyados en su gracia providente, se nos otorga el don de vivir constitutivamente orientados hacia la plenitud:

«Es la experiencia del "ya y todavía no" en la vida cristiana. El crecimiento del cristiano no se explica por la sola atracción que tiene el hombre hacia el futuro, hacia la plenitud; cuenta con un factor de importancia capital: la gracia recibida, la santificación operada en el bautismo. Esta vida nueva es la que impulsa, la que actúa desde dentro, porque lleva en su naturaleza la expansión hasta la consumación total en Dios después de la muerte» ${ }^{69}$.

\subsection{LA OBEDIENCIA COMO CONFIGURACIÓN}

Finalmente, la tercera de las dimensiones de espiritualidad — junto con la búsqueda y la acción - remite a la primacía de Dios dentro de la vida espiritual. Desde el comienzo de nuestra reflexión hemos descrito la espiritualidad como una fe vivida en Cristo y una entrega vivida a Dios por el Espíritu. Pero ni la búsqueda profunda de Dios ni la audacia evangélica de nuestras decisiones son suficientes para vivir una espiritualidad misionera si no se encuadran en una relación filial en la que el Padre tenga la primera y la última palabra. Para que nuestra vida cristiana sea auténtica es Dios quien ha de tomar la iniciativa, es su providencia amorosa la que debe marcar la pauta.

68 Ibid., n. 88.

69 Saturnino Gamarra. Teología espiritual. 2. ${ }^{\text {a }}$ ed. Madrid: BAC, 2004, 182; cf. Federico Ruiz Salvador. Caminos del Espíritu. Compendio de Teología espiritual. Madrid: EDE, 1974, 458-460; Juan Luis Ruiz de la Peña. El don de Dios. Antropología teológica especial. 3. ${ }^{\text {a }}$ ed. Santander: Sal Terrae, 2001, 390, donde se explica el dinamismo de la gracia en su pulsión escatológica: «Ella es ya el fin incoado o, como decían los medievales, inchoatio glorice», en palabras memorables del cardenal Newman «la gracia es la gloria en el exilio; la gloria es la gracia en el hogar». 
La obediencia nos habla de este modo particular de filiación que estamos llamados a vivir en Cristo y como Cristo. Todo el Evangelio revela el modo en que Jesús vive el amor del Padre: como expresión unitaria de una proximidad y obediencia máximas ${ }^{70}$. Su abandono confiado no estuvo reñido con el reconocimiento efectivo de la soberanía del Padre, eterna fuente de amor. De modo análogo, el dinamismo del voto de obediencia nos invita a integrar en nosotros esta misma experiencia unitaria de filiación. Se trata de configurar nuestro ser y nuestro obrar con la voluntad de Dios, permitiéndole tomar las riendas de nuestra biografía para ser hijos en el Hijo (cf. Rom 8,15-16). Puede costarnos la vida entera llegar a descubrirlo y asimilarlo en propia carne, pero hemos de creer en la fecundidad imperecedera de la obediencia en cuanto configuración con la forma de vida de Jesús, el Hijo por antonomasia. Una obediencia que pasa por el servicio denodado, por la paciencia constante e incluso por la entrega total de la cruz (Flp 2,8), pero - sobre todo- por la experiencia de saberse infinitamente amado por el Padre.

Las convergencias de la obediencia con la pobreza y la castidad son profundas y muy palpables, puesto que, en su ultimidad, todas nos remiten a la forma de vida misma de Jesús. Con todo, en lo que respecta a la espiritualidad misionera, podríamos cifrar en dos las notas más propias que aporta la obediencia: por una parte, la llamada a vivir la fe desde la primacía del Evangelio y, por otra, la urgencia de disponer la vida en dedicación total, a imagen de Cristo misionero.

\section{a) La primacía del Evangelio: la fe}

En primer lugar, la obediencia es, para una espiritualidad misionera, una llamada a la fe. Una de las características de nuestro tiempo es la preocupación por la propia autonomía, la suspicacia ante todo aquello que suene a un menoscabo de la libertad o el temor a perder la propia independencia. El sobredimensionamiento actual de este tipo de preocupaciones y recelos conducen casi siempre a un aislamiento estéril y a la incapacidad para vivirnos como comunidad humana. Esto, que repercute en la sociedad en su conjunto, afecta también a la conciencia

70 Cf. Jeremias, 17-89; Jacques Schlosser. El Dios de Jesús. Estudio exegético. Salamanca: Sígueme, 1995, 105-213; Santiago Guijarro. "Dios Padre en la actuación de Jesús”. Estudios Trinitarios 34, n. ${ }^{\circ} 1$ (2000): 33-69. 
creyente y consagrada. Frente a ello, el dinamismo evangélico de la obediencia puede ayudarnos a cultivar la fe como confianza radical en Dios, en su providencia y en su voluntad, evitando así la ingenua tentación de aspirar a una vida lograda de espaldas a Dios o a lomos de un egoísmo destructor:

«La persona consagrada, con su misma existencia, muestra la posibilidad de un camino distinto de realización de la propia vida; un camino donde Dios es la meta, su Palabra la luz y su voluntad la guía; un camino en que se avanza con serenidad, sabiéndose seguros de estar sostenidos por las manos de un Padre acogedor y providente; donde uno está acompañado de hermanos y hermanas y empujado por el Espíritu, que quiere y puede saciar los deseos sembrados por el Padre en el corazón de cada uno. Es esta la primera misión de la persona consagrada: testimoniar la libertad de los hijos de Dios, una libertad modelada sobre la de Cristo, el hombre libre para servir a Dios y a los hermanos» ${ }^{71}$.

Si lo miramos desde Jesús, el modo obediente de vivir la filiación divina destaca por la inmensa libertad en que se despliega. En este punto, la espiritualidad misionera está llamada a adherirse al Evangelio desde la fe para integrar en sí misma el camino liberador de Jesús. Es el camino del consentimiento en el Espíritu, por el que vamos aprendiendo del Padre los tiempos y los modos en que se ha de buscar y actuar. Desde esta perspectiva, la incomprensibilidad de la vida no produce únicamente perplejidad, sino que nos capacita para pronunciar una respuesta personal y libre al don de Dios. La dimensión fiducial de la existencia cristiana, su ser creyente, se nutre de la convicción interior según la cual podemos responder ante el misterio de la existencia consintiendo libremente a la primacía de Dios y del Evangelio en la propia vida:

«Es saber con certeza que quien se ofrece y se entrega a Dios por amor seguramente será fecundo (cf. Jn 15,5). Tal fecundidad es muchas veces invisible, inaferrable, no puede ser contabilizada. Uno sabe bien que su vida dará frutos, pero sin pretender saber cómo, ni dónde, ni cuándo. Tiene la seguridad de que no se pierde ninguno de sus trabajos realizados con amor, no se pierde ninguna de sus preocupaciones sinceras por los demás, no se pierde ningún acto de amor a Dios, no se

${ }^{71}$ CIVCSVA. "Faciem tuam, Domine, requiram». El servicio de la autoridad y la obediencia, n. 15. 
pierde ningún cansancio generoso, no se pierde ninguna dolorosa paciencia. [...] A veces nos parece que nuestra tarea no ha logrado ningún resultado, pero la misión no es un negocio ni un proyecto empresarial, no es tampoco una organización humanitaria, no es un espectáculo para contar cuánta gente asistió gracias a nuestra propaganda; es algo mucho más profundo, que escapa a toda medida. Quizás el Señor toma nuestra entrega para derramar bendiciones en otro lugar del mundo donde nosotros nunca iremos. El Espíritu Santo obra como quiere, cuando quiere y donde quiere; nosotros nos entregamos, pero sin pretender ver resultados llamativos. Sólo sabemos que nuestra entrega es necesaria. Aprendamos a descansar en la ternura de los brazos del Padre en medio de la entrega creativa y generosa. Sigamos adelante, démoslo todo, pero dejemos que sea Él quien haga fecundos nuestros esfuerzos como a Él le parezca» ${ }^{72}$.

A fin de cuentas, ¿quién hubiera presentido que la obediencia hasta la cruz fuera a representar el culmen supremo de la misión de Jesús y su mayor fuente de fecundidad? Y, sin embargo, en toda su paradoja, el consentir fiducial del Hijo revelaba por entero el amor del Padre, que ofrecía cuanto podía darnos - el Hijo de sus entrañas-, al mismo tiempo que nos abría de una vez para siempre las fuentes de la salvación ${ }^{73}$. La espiritualidad misionera necesita volver una y otra vez a la cima del Calvario para descubrir en ella el paradigma de su vocación. "Con su misma forma de vida, el Señor Jesús nos hace comprender que misión y obediencia se implican mutuamente». En el fondo, «toda la vida de Jesús es misión del Padre», más aún, «Él es la misión del Padre», por eso, podemos decir que «se está en misión cuando, lejos de perseguir la autoafirmación, ante todo se deja uno conducir por el deseo de realizar la adorable voluntad de Dios» ${ }^{74}$. Para algunos suene quizá demasiado «espiritual»o «piadoso»,

72 Francisco. Evangelii gaudium, n. 279.

73 Olegario González de Cardedal. Cristología. Madrid: BAC, 2001, 115: «Si en cuanto obra de los hombres la muerte de Jesús es un crimen y en cuanto obra del propio Jesucristo es un servicio y sacrificio por sus hermanos, en cuanto obra de Dios es el Don del Padre, que se entrega a sí mismo entregando su Primogénito a todos los hermanos para que la vida de él se convierta en la vida de ellos, para que con su potencia santificante y sanadora destruya sus pecados, los integre a la filiación y les confiera el Espíritu. La muerte de Cristo no es una necesidad histórica ni un castigo moral ni una exigencia jurídica. Antes que la muerte de un hombre ante Dios, es la muerte del Hijo en la que Dios se dice y se da a los hombres».

74 CIVCSVA. "Faciem tuam, Domine, requiram", nn. 23-24. 
pero ¿acaso no es esto mismo lo que nos permite comprender la vida desde su incomprensibilidad — valga la paradoja-?

\section{b) En «dedicación total»: conformarse a Cristo misionero}

En segundo lugar, la obediencia es, para una espiritualidad misionera, una llamada a la dedicación total. El capítulo III de la exhortación Vita consecrata está dedicado al «servicio de la caridad»o, lo que es lo mismo, a la misión de la vida consagrada como «epifanía del amor de Dios en el mundo». El seguimiento de Cristo que realiza todo cristiano pasa por la configuración con el Hijo y por la continuación de su misión. Una vez más, se manifiesta la relación intrínseca entre la comunión con Dios y la misión en el mundo. Aquello que determina todo discipulado cristiano, Vita consecrata lo enfatiza al referirse a «cuantos son llamados a seguir a Cristo "más de cerca" en la forma característica de la vida consagrada, haciendo de Él el "todo" de su existencia la consagración religiosa $»^{75}$. Por eso, en la llamada al seguimiento "está incluida la tarea de dedicarse totalmente a la misión; más aún, la misma vida consagrada, bajo la acción del Espíritu Santo, que es la fuente de toda vocación y de todo carisma, se hace misión, como lo ha sido la vida entera de Jesús» ${ }^{76}$.

Bien entendida, la obediencia evangélica nos capacita para llevar a cabo nuestra misión, no tanto por las disposiciones inmediatas que pueda implicar (el acatamiento expedito de las órdenes de un superior), cuanto por configurar la propia existencia con la forma de vida de Jesús: «en efecto, antes que en las obras exteriores, la misión se lleva a cabo en el hacer presente a Cristo en el mundo mediante el testimonio personal». A fin de cuentas, "este es el quehacer principal de la vida consagrada», ya que, «cuanto más se deja conformar a Cristo, más lo hace presente y operante en el mundo para la salvación de los hombres» ${ }^{77}$.

Para que nuestra vida pueda conformarse a la de Cristo en la misión, la Exhortación nos habla del necesario vínculo con la espiritualidad: «es necesario, pues, estar abiertos a la voz interior del Espíritu que invita a acoger en lo más hondo los designios de la Providencia». Es el Espíritu el que «llama a la vida consagrada para que elabore nuevas respuestas

\footnotetext{
75 Juan Pablo II. Vita consecrata, n. 72a.

76 Ibid.

77 Ibid., n. $72 \mathrm{ab}$.
} 
a los nuevos problemas del mundo de hoy ${ }^{78}$. En este sentido hemos de entender los llamados «signos de los tiempos». No se trata de buscar la innovación a cualquier precio, en orden a superar la rutina o el hastío que puede acarrear la misión. Para poder percibir en cada tiempo los signos de Dios es preciso un cierto acostumbramiento a su voluntad, así como una buena dosis de finura espiritual. Vividas desde una espiritualidad misionera, las encrucijadas del mundo actual son «un reclamo divino del que sólo las almas habituadas a buscar en todo la voluntad de Dios saben percibir con nitidez y traducir después con valentía en opciones coherentes ${ }^{79}$.

Como hemos ido viendo, nuestra espiritualidad está llamada a integrar en sí el dinamismo misionero del amor de Dios a imagen de Jesús. La disponibilidad esperanzada de la pobreza y la fecundidad valiente de la castidad tienen su correlato en la configuración integral que nos procura la obediencia. Podríamos decir que, al ser una participación ya desde ahora en la vida misma de Dios, la espiritualidad ha de ser inevitablemente misionera, llamada a salir de sí para engendrar nueva vida. La obediencia nos enseña, por tanto, a acostumbrar nuestro corazón, de modo que vivamos en total disposición para recibir el don de Dios y para compartirlo con todos y en todo tiempo. De suerte que el amor de Dios nos llegue a nosotros y al mundo de hoy tal como Él nos lo quiere entregar, en toda su plenitud.

Como puede comprobarse, a lo largo de estos tres apartados hemos ido desgranando diversos aspectos de una espiritualidad que no puede ser sino misionera y de una misión que, en el fondo, no es sino espiritual. Todo ello para fundamentar sólidamente el empeño misionero de la Iglesia de nuestros días. No faltarán quienes califiquen de «obsesión» el empeño de Francisco por poner a la Iglesia en estado de misión. Sin embargo, hemos de convenir en que dicha insistencia no es fruto de una moda pasajera, sino que nace de las constantes de su pensamiento y de la misma concepción que la Iglesia va teniendo de sí misma.

En realidad, todo en la Iglesia ha de estar orientado a la misión porque ella misma es misión. Y, en este sentido, la apertura misionera se convierte en piedra de toque de toda espiritualidad. No podemos renunciar nunca a este discernimiento, porque una Iglesia deficitaria en la misión

\footnotetext{
78 Ibid., n. 73 b.

79 Ibid.
} 
revelaría un déficit más profundo en la espiritualidad, y viceversa. Recurriendo a imágenes sugerentes, el papa nos está diciendo con razón que una Iglesia que no vive en clave misionera no está viviendo rectamente la fe o la espiritualidad. O, por expresarlo de otro modo, una Iglesia tal estaría enconada en la búsqueda y el deseo de una vida espiritual que, en el fondo, no sería cristiana, pues no se traduciría en decisiones concretas y consecuentes, ni estaría informada por la obediencia filial que consiente al modo propio de ser de Dios.

\section{A MODO DE CONCLUSIÓN. CONVERSIÓN AL EVANGELIO Y FIDELIDAD EN LA INCOMPRENSIBILIDAD}

Sin ser exhaustivos, hemos tratado de esbozar algunas de las mociones más importantes del Espíritu para la Iglesia actual, buscando evidenciar los fundamentos en los que se arraiga la espiritualidad en relación con la misión. Lo hemos hecho situándonos bajo el amparo teológico de la generación conciliar y postconciliar, que trató de integrar lo misionero como algo propio en la autoconciencia eclesial. Porque, en el fondo, — como decía J. Daniélou— «la espiritualidad misionera no es más que la misma espiritualidad cristiana, considerada en toda su amplitud» ${ }^{80}$.

Por ello, quisiéramos terminar esta aportación volviendo a Rahner, con quien hemos empezado, y su particular visión de la llamada del Espíritu para nuestra época. Concluye el teólogo:

«Se ha de evitar considerar lo nuevo y lo antiguo como compartimentos estancos dentro de la espiritualidad cristiana: lo nuevo sólo es auténtico cuando conserva lo antiguo; y lo antiguo sólo sigue teniendo vida cuando es vivido en forma nueva. En lo antiguo y en lo nuevo ha de mantenerse siempre inmutable lo que ha sido antes,

\footnotetext{
80 Jean Daniélou. "Importancia actual del problema misionero". En Trilogía de la salvación, 295-311: "Hay una manera de vivir nuestro cristianismo, encerrándonos en los estrechos límites de la comunidad de que formamos parte — sea nuestra familia o, incluso, nuestra patria-. Considerar el cristianismo desde este punto de vista es renunciar a verlo en sus auténticas perspectivas. El cristianismo es católico por definición —es decir, que por naturaleza abarca al mundo entero-, y una espiritualidad cristiana que no se encuentre orientada fundamentalmente a la edificación del Cuerpo Místico total no es una espiritualidad católica» (295).
} 
lo es actualmente y lo será siempre - y sobre lo cual nunca cabe insistir demasiado-: la bendita incomprensibilidad de la vida, Dios, el misterio del Crucificado y Resucitado, la gracia divina en y sobre toda la vulgaridad de la vida diaria, la esperanza en la vida eterna, que es la incomprensibilidad misma de Dios ahora revelada. Donde se da todo esto de forma vital, se da un cristiano y un buen cristiano. Y lo mismo ocurrirá en el futuro» ${ }^{81}$.

Cuando los temores al cambio o, mejor dicho, al crecimiento, los vivimos desde el lamento, no solo malgastamos la oportunidad que la vida nos brinda para tejer una biografía habitada por Dios y vivida «por Él, con Él y en Él», sino que además nuestros recelos e inercias nos impiden ver cómo Dios nos precede a cada paso. En efecto, si hemos hablado de la espiritualidad como búsqueda, como acción y como consentimiento, es porque nos sabemos creados «a imagen y semejanza» del Misterio por excelencia, del incomprensible por antonomasia: tal fue su pasión por nosotros y el deseo de otorgarnos su amor que desde siempre quiso buscarnos; tal fue su "grande y muy determinada determinación ${ }^{82}$ que de una vez por todas se decidió a redimirnos y salvarnos; tal su consentimiento que con la gracia providente de su Espíritu nos sostiene y colma a cada paso del «misterioso» camino de nuestra vida. Él nos precede, nos acompaña y nos sostiene. Por eso, nos invita a abrazar la misión, no como un "efecto» entre otros muchos de nuestra relación viva con Dios, sino como el modo de tejer una biografía escrita de su mano en apertura de amor al mundo.

Hoy como ayer, inmersos en los cambios de nuestra historia, asomados al misterio incomprensible de la vida... qué distinto, en cambio, sabernos precedidos y habitados, sostenidos y acompañados; para acoger entonces de labios de Jesús aquellas últimas palabras con las que Mateo corona su testimonio:

«Id, pues, y haced discípulos a todos los pueblos, bautizándolos en el nombre del Padre y del Hijo y del Espíritu Santo; enseñándoles a guardar todo lo que os he mandado. Y sabed que yo estoy con vosotros todos los días, hasta el final de los tiempos» (Mt 28,19-20).

81 Rahner, 35.

82 Teresa de Jesús. Camino de perfección [autógrafo de Valladolid], 21,2 [En Obras completas. 5. ${ }^{\mathrm{a}}$ ed. Madrid: EDE, 2000, 721]. 


\section{BIBLIOGRAFÍA}

Balthasar, Hans Urs von. "El Evangelio como norma y criterio de toda espiritualidad en la Iglesia”. En Spiritus Creator. Ensayos teológicos III. Madrid: Encuentro - Cristiandad, 2004, 233-247 [or.: "Das Evangelium als Norm und Kritik aller Spiritualität in der Kirche". Concilium 1, n. 9 (1965): 715-722].

Balthasar, Hans Urs von. Teodramática 1. Prolegómenos. Madrid: Encuentro, 1990.

Balthasar, Hans Urs von. Teodramática 4. La acción. Madrid: Encuentro, 1995. Barth, Karl. Dogmatique. Vol. IV/1, t. 3. Genève: Labor et Fides, 1967.

Benedicto XV. Maximum illud (1919).

Benedicto XVI. Deus caritas est (2005).

Benedicto XVI. Discurso a los superiores y superioras generales (26/11/2010). Benedicto XVI. Sacramentum caritatis (2007).

Blázquez, Ricardo. La Iglesia. Misterio, comunión, misión. Salamanca: Sígueme, 2017.

Castellano Cervera, Jesús. "Spiritualità e missione alla luce della Esortazione apostolica 'Vita consecrata”". En Spiritualità e missione. Il "proprium» della vita religiosa alla luce della Esortazione postsinodale «Vita consecrata», dirigido por Conferenza Italiana dei Superiori Maggiori, 39-74. Roma: Rogate, 1997.

Catecismo de la Iglesia Católica (1992).

Chatterjee, Margaret. The Concept of Spirituality. Ahmedabad: Allied Publishers, 1989.

CIVCSVA. "Faciem tuam, Domine, requiram». El servicio de la autoridad y la obediencia (2008).

Concilio Vaticano II. Ad gentes divinitus (1965).

Concilio Vaticano II. Gaudium et spes (1965).

Concilio Vaticano II. Lumen gentium (1964).

Congar, Yves. "Principes doctrinaux". En Vatican II. L'activité missionnaire de l'Église. Décret "Ad gentes», dirigido por Johannes Schütte. 185-221. Paris: Cerf, 1967.

Cordovilla, Ángel. Crisis de Dios y crisis de fe. Volver a lo esencial. Santander: Sal Terrae, 2012.

Cordovilla, Ángel. "Como el Padre me envió, así os envío yo». Teología y espiritualidad del ministerio apostólico presbiteral. Salamanca: Sígueme, 2019. 
Daniélou, Jean. Trilogía de la salvación. Madrid: Guadarrama, 1964.

Dianich, Severino. Iglesia en misión. Hacia una eclesiología dinámica. Salamanca: Sígueme, 1988.

Francisco. Carta con ocasión del centenario de la promulgación de la Carta apostólica "Maximum illud» sobre la actividad desarrollada por los misioneros en el mundo (22/10/17).

Francisco. Evangelii gaudium (2013).

Galli, Carlos María. "La reforma misionera de la Iglesia según el papa Francisco. La eclesiología del pueblo de Dios evangelizador". En $L a$ reforma y las reformas en la Iglesia, dirigido por Antonio Spadaro y Carlos María Galli, 51-77. Santander: Sal Terrae, 2016.

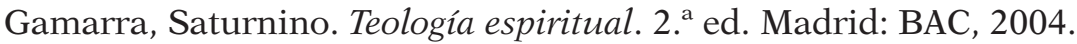

González de Cardedal, Olegario. "Poder y ternura”. En ABC (23/12/2018): 3.

González de Cardedal, Olegario. Cristología. Madrid: BAC, 2001.

Greshake, Gisbert. ... wie man in der Welt leben soll. Grundfragen christlicher Spiritualität. Würzburg: Echter, 2009.

Guijarro, Santiago. "Dios Padre en la actuación de Jesús". En Estudios Trinitarios 34, n. ${ }^{\circ} 1$ (2000): 33-69.

Jeremias, Joachim. ABBÁ. El mensaje central del Nuevo Testamento. 5. ${ }^{a}$ ed. Salamanca: Sígueme, 1999.

Juan Pablo II. Novo millenio ineunte (2001).

Juan Pablo II. Pastores dabo vobis (1992).

Juan Pablo II. Redemptoris missio (1990).

Juan Pablo II. Slavorum apostoli (1985).

Juan Pablo II. Vita consecrata (1996).

Kasper, Walter. Jesús, el Cristo. Salamanca: Sígueme, 1976.

Le Guillou, Marie-Joseph. "La vocación misionera de la Iglesia". En La Iglesia del Vaticano II. Estudios en torno a la Constitución conciliar sobre la Iglesia, dirigido por Guillermo Baraúna. Vol. 1, 697-712. 2. a ed. Barcelona: Juan Flors, 1966.

Lubac, Henri de. "Credo Ecclesiam”. En Sentire Ecclesiam. Das Bewusstsein von der Kirche als gestaltende Kraft der Frömmigkeit. Festschrift für H. Rahner, dirigido por Jean Daniélou y Herbert Vorgrimler, 13-16. Freiburg im Breisgau: Herder, 1961.

Lubac, Henri de. Las Iglesias particulares en la Iglesia universal. Salamanca: Sígueme, 1974.

Lubac, Henri de. La fe cristiana. Ensayo sobre la estructura del Símbolo de los Apóstoles. 2. ${ }^{\mathrm{a}}$ ed. Salamanca: Secretariado Trinitario, 2012. 
Lubac, Henri de. Meditación sobre la Iglesia. 2. a ed. Madrid: Encuentro, 2011. Madrigal, Santiago. Iglesia es Caritas. La eclesiología teológica de Joseph Ratzinger-Benedicto XVI. Santander: Sal Terrae, 2008.

Madrigal, Santiago. "La actividad misionera de la Iglesia, ad gentes divinitus missa ut sit sacramentum salutis universale". En El Concilio Vaticano II. Una perspectiva teológica, dirigido por Vicente Vide y José Ramón Villar, 355-398. Madrid: San Pablo, 2013.

Madrigal, Santiago. El giro eclesiológico en la recepción del Vaticano II. Santander: Sal Terrae, 2017.

Marion, Jean-Luc. "La crise et la Croix". Communio. Revue Catholique Internationale 8, n. ${ }^{\circ} 4$ (1983): 8-22.

Martinelli, Paolo. Seguir hoy a Cristo. Vida sacerdotal y consejos evangélicos. Madrid: Encuentro, 2018.

Pablo VI. Evangelii nuntiandi (1975).

Pacho, Eulogio. "Definición de la 'espiritualidad'. Respuestas y tratamientos". Burgense 34, n. ${ }^{\circ} 1$ (1993): 281-302.

Pío XI. Rerum Ecclesice (1926).

Pío XII. Fidei donum (1957).

Prado Postigo, Adrián de. Con infinito exceso. La fe cristiana a la luz de un Amor sobreabundante. Santander: Sal Terrae, 2016.

Prado Postigo, Adrián de. De Dios, a quien amar. La lógica del mérito en De diligendo Deo de san Bernardo. Burgos: Monte Carmelo, 2019.

Rahner, Karl. "Espiritualidad antigua y actual". En Escritos de teología. Vol. 7. Madrid: Taurus, 1969, 13-35 [or:: "Frömmigkeit heute und morgen". Geist und Leben 39/5 (1966): 326-34; "Frömmigkeit früher und heute". En Schriften zur Theologie VII. Zur Theologie des geistlichen Lebens. Einsiedeln - Zürich - Köln: Benziger, 1966, 11-31; Sämtliche Werke. Vol. 23, 31-46].

Ratzinger, Joseph. "¿Iglesia abierta al mundo? Reflexiones sobre la estructura del concilio Vaticano II". En Obras completas VII/2. Sobre la enseñanza del concilio Vaticano II. Madrid: BAC, 2016, 922-944.

Richebächer, Wilhelm. "Missio Dei: The Basis of Mission Theology or a Wrong Path?”. International Review of Mission 92, n. ${ }^{\circ} 4$ (2003): 588605. DOI: https://doi.org/10.1111/j.1758-6631.2003.tb00431.x

Rosin, H. H. "Missio Dei»: An Examination of the Origin, Contents, and Function of the Term in Protestant Missiological Discussion. Leiden: Interuniversity Institute for Missiological and Ecumenical Research Department of Missiology, 1972. 
Rossel, Jacques. "From a Theology of Crisis to a Theology of Revolution?'. Karl Barth, Mission and Missions. The Ecumenical Review 21, n. 3 (1969): 204-215. DOI: https://doi.org/10.1111/j.1758-6623.1969. tb02270.x

Ruiz de la Peña, Juan Luis. El don de Dios. Antropología teológica especial. 3. ${ }^{a}$ ed. Santander: Sal Terrae, 2001.

Ruiz Salvador, Federico. Caminos del Espíritu. Compendio de Teología espiritual. Madrid: EDE, 1974.

Schlosser, Jacques. El Dios de Jesús. Estudio exegético. Salamanca: Sígueme, 1995.

Schürmann, Heinz. El destino de Jesús: su vida y su muerte. Salamanca: Sígueme, 2003.

Singh Sant, Kirpal. Was ist Spiritualität? Bern: Origo, 1983.

Solignac, Aimé. "Spiritualité (I. Le mot et l'histoire)". En Dictionnaire de Spiritualité ascétique et mystique. Doctrine et histoire, dirigido por Marcel Viller y Ferdinand Cavallera. Vol. 14, 1142-1160. Paris: Beauchesne, 1990.

Teresa de Jesús. Obras completas. 5. a ed. Madrid: EDE, 2000.

Tinsley, Lucy. The French Expressions for Spirituality and Devotion. A Semantic Study. New York: Catholic University of America Press, 1953.

Uríbarri, Gabino. Santidad misionera. Fuentes, marco y contenido de Gaudete et exsultate. Santander: Sal Terrae, 2019.

Waaijman, Kees. Espiritualidad. Formas, fundamentos y métodos. Salamanca: Sígueme, 2011.

Wickeri, Philip Lauri. "Mission from the Margins. The Missio Dei in the Crisis of World Christianity". International Review of Mission 93, n. ${ }^{\circ}$ 369 (2004): 182-198. DOI: https://doi.org/10.1111/j.1758-6631.2004. tb00452.x 